\title{
Simulation of particle size distribution with a global aerosol model: contribution of nucleation to aerosol and $\mathrm{CCN}$ number concentrations
}

\author{
F. Yu and G. Luo \\ Atmospheric Sciences Research Center, State University of New York, 251 Fuller Road, Albany, New York 12203, USA \\ Received: 30 March 2009 - Published in Atmos. Chem. Phys. Discuss.: 30 April 2009 \\ Revised: 18 September 2009 - Accepted: 28 September 2009 - Published: 16 October 2009
}

\begin{abstract}
An advanced particle microphysics model with a number of computationally efficient schemes has been incorporated into a global chemistry transport model (GEOSChem) to simulate particle number size distributions and cloud condensation nuclei $(\mathrm{CCN})$ concentrations in the atmosphere. Size-resolved microphysics for secondary particles (i.e., those formed from gaseous species) and sea salt has been treated in the present study. The growth of nucleated particles through the condensation of sulfuric acid vapor and equilibrium uptake of nitrate, ammonium, and secondary organic aerosol is explicitly simulated, along with the scavenging of secondary particles by primary particles (dust, black carbon, organic carbon, and sea salt). We calculate secondary particle formation rate based on ion-mediated nucleation (IMN) mechanism and constrain the parameterizations of primary particle emissions with various observations. Our simulations indicate that secondary particles formed via IMN appear to be able to account for the particle number concentrations observed in many parts of the troposphere. A comparison of the simulated annual mean concentrations of condensation nuclei larger than $10 \mathrm{~nm}(\mathrm{CN} 10)$ with those measured values show very good agreement (within a factor of two) in near all 22 sites around the globe that have at least one full year of CN10 measurements. Secondary particles appear to dominate the number abundance in most parts of the troposphere. Calculated CCN concentration at supersaturation of $0.4 \%$ (CCN0.4) and the fraction of CCN0.4 that is secondary $\left(f_{\mathrm{CCN}}^{\mathrm{sec}}\right)$ have large spatial variations. Over the middle latitude in the Northern Hemisphere, zonally averaged CCN0.4 decreases from $\sim 400-700 \mathrm{~cm}^{-3}$ in the boundary layer (BL) to below $100 \mathrm{~cm}^{-3}$ above altitude of $\sim 4 \mathrm{~km}$, the correspond-
\end{abstract}

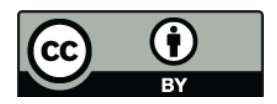

Correspondence to: $\mathrm{F}$. Yu (yfq@asrc.cestm.albany.edu) ing $f_{\text {CCN }}^{\text {sec }}$ values change from $50-60 \%$ to above $\sim 70 \%$. In the Southern Hemisphere, the zonally averaged CCNO.4 is below $200 \mathrm{~cm}^{-3}$ and $f_{\mathrm{CCN}}^{\mathrm{sec}}$ is generally above $60 \%$ except in the BL over the Southern Ocean.

\section{Introduction}

Atmospheric particles perturb the Earth's energy budget indirectly by acting as cloud condensation nuclei (CCN) and thus changing cloud properties and influencing precipitation. The magnitude of the aerosol indirect radiative forcing (IRF) represents the dominate uncertainty in assessing climate change (NRC, 2005; IPCC, 2007; Chin et al., 2009). The aerosol indirect radiative forcing is largely determined by the number abundance of particles that can act as CCN (e.g., Twomey, 1977; Albrecht, 1989; Charlson et al., 1992). An increase in the number and a decrease in the size of cloud droplets (for fixed liquid water content) resulted from the increase of aerosol number concentrations will increase cloud optical depth and cloud albedo (first indirect aerosol effect). The change of cloud drop number concentration that results from the increase in aerosol concentration can also affect the cloud liquid water content, cloud amount, cloud lifetime, and precipitation efficiency (second indirect aerosol effect). At a given supersaturation ratio, $\mathrm{CCN}$ number concentrations depend on the number size distribution and composition of atmospheric particles. Pan et al. (1998) showed that aerosol size parameters are the leading contributors to the uncertainty of calculated IRF by anthropogenic sulfate aerosols and suggested that a size-resolved global aerosol model should be an important step toward reducing the uncertainty.

The particles in the troposphere either come from in-situ nucleation (i.e, secondary particles) or direct emission (i.e.,

Published by Copernicus Publications on behalf of the European Geosciences Union. 
primary particles). Nucleation frequently observed throughout the troposphere is believed to be an important source of atmospheric particles (e.g., Yu et al., 2008). While freshly nucleated particles have a size of only a few nanometers, a non-trivial fraction of these particles is known to be able to grow to $\mathrm{CCN}$ size under favorable conditions. A number of recent studies have employed global size-resolved aerosol microphysics models to study the contributions of primary and secondary particles to $\mathrm{CCN}$ concentrations.

Different parameterizations of primary particle emissions have been reported to have substantial impact on predicted CCN abundance (Adams and Seinfeld, 2002, 2003; Spracklen et al., 2005a; Pierce and Adams, 2006; Pierce et al., 2007). For example, Adams and Seinfeld (2003) showed that a few percent of anthropogenic sulfur emitted as particulate sulfate (to represent the sub-grid nucleation process) increases CCN concentrations in polluted areas by up to $\sim 200$ $500 \%$. Spracklen et al. (2005b) showed that global mean sulfate and sea salt derived $\mathrm{CCN}$ concentrations change by up to $27 \%$ in marine boundary layer and by more than $100 \%$ over some continental regions when the fraction of anthropogenic $\mathrm{SO}_{2}$ emitted as particulates is increased from 0 to 5\%. Pierce et al. (2007) showed that the inclusion of carbonaceous aerosol particles (assumed to have number median diameter of $\sim 25 \mathrm{~nm}$ ) can increase $\mathrm{CCN}$ concentrations $(0.2 \%)$ by $65-90 \%$ in the globally averaged surface layer. While these results highlight the potential important contribution of primary particles to $\mathrm{CCN}$ in some regions, they cannot be used to infer that the contribution of secondary particles is not important because of the large uncertainties in the size and amount of primary particles (note that primary sulfate particles in these studies are actually secondary particles nucleated in sub-grid plumes). More importantly, the above mentioned studies are likely to significantly under-estimate the contribution of secondary particles to $\mathrm{CCN}$ because the nucleation rates in these studies are calculated with $\mathrm{H}_{2} \mathrm{SO}_{4}$ $\mathrm{H}_{2} \mathrm{O}$ binary homogeneous nucleation (BHN) theory which is known to predict negligible secondary particle formation in the lower troposphere and cannot explain nucleation events frequently observed around the globe (Yu and Turco, 2008). Pierce and Adams (2009) showed that uncertainties in nucleation, primary emissions and secondary organic aerosol (SOA) condensation may all influence predictions of $\mathrm{CCN}$ and emphasized the necessity to reduce the uncertainties in these processes in order to better understand the aerosol indirect effect.

The global aerosol simulations reported in Spracklen et al. (2006, 2008), Makkonen et al. (2008), and Pierce and Adams (2009), based on an empirically parameterized activation-type nucleation mechanism (linear dependence of nucleation rate $J$ on sulfuric acid gas concentration: $J=A$ $\left[\mathrm{H}_{2} \mathrm{SO}_{4}\right]$ with $A$ as pre-factor), showed that boundary layer (BL) nucleation is necessary to improve the agreement between modeled and observed particle number concentrations. Spracklen et al. (2008) concluded that BL nucleation is an important global source of $\mathrm{CCN}$ and increases global BL CCN concentrations at $0.2 \%$ supersaturation by $3-20 \%$ and $\mathrm{CCN}$ at $1 \%$ supersaturation by $5-50 \%$. Based on their sensitivity study, Makkonen et al. (2008) pointed out that the predicted CCN concentrations are sensitive to the choice of the nucleation mechanism.

Wang and Penner (2009) assessed how nucleation affects the CCN concentration and aerosol indirect forcing, using a global aerosol model that calculates the nucleation in and above the boundary layer with an empirical activation-type nucleation scheme and binary homogeneous nucleation theory, respectively. Wang and Penner (2009) showed that the inclusion of an empirical BL activation-type nucleation mechanism increases the global average $\mathrm{CCN}$ concentrations in the BL by $31.4 \%$ without primary sulfate particle emission and by $5.3 \%$ with primary sulfate particle emission. Wang and Penner (2009) also found that the aerosol indirect radiative forcing from various treatments of aerosol nucleation ranges from -1.22 to $-2.03 \mathrm{~W} / \mathrm{m}^{2}$ and emphasized the importance of better quantifying aerosol nucleation mechanisms in reducing uncertainty in the assessment of aerosol indirect radiative forcing.

It is clear from these recent studies (e.g., Spracklen et al., 2006, 2008; Makkonen et al., 2009; Wang and Penner, 2009) that nucleation is an important source of global CCN and that aerosol indirect effect is sensitive to the nucleation process. It should be noted that the activation-type nucleation mechanism employed in these studies is a regression parameterization of nucleation events observed in a number of locations. The values of pre-factor $(A)$ derived from different sets of nucleation measurements vary significantly (up to three orders of magnitude) (Riipinen et al., 2007; Kuang et al., 2008), indicating that parameters other than $\left[\mathrm{H}_{2} \mathrm{SO}_{4}\right]$ also affect atmospheric nucleation rates. Due to the overprediction of the activation nucleation scheme (derived empirically from surface observation) at high altitudes, the application of this scheme is generally limited to the boundary layer (Spracklen et al., 2008; Makkonen et al., 2009; Wang and Penner, 2009). A more robust nucleation mechanism with clear physics and state-of-the-art thermodynamics is apparently needed to improve the representation of the nucleation process in the global atmosphere.

Based on an up-to-date kinetically consistent ion-mediated nucleation (IMN) model incorporating recently available thermodynamic data and schemes, Yu (2006) concluded that ions can lead to significant particle formation not only in the upper troposphere but also in the lower troposphere (including the boundary layer). The involvement of ions in atmospheric particle formation has been unequivocally confirmed by the 3 -year ion mobility measurements (Hirsikko et al., 2007) and 1-year measurements of the excess charge on freshly nucleated particles taken in boreal forests (Laakso et al., 2007; Gagné et al., 2008), although the relative contribution of ion and neutral nucleation remains controversial. Kulmala and colleagues argued that IMN contributes only 
up to $\sim 10 \%$ to the boreal forest nucleation (Laakso et al., 2007; Kulmala et al., 2007; Gagné et al., 2008; Boy et al., 2008). However, Yu and colleagues concluded that IMN appears to be the dominant nucleation mechanism in at least a large fraction of nucleation events observed in the boreal forests (Yu and Turco, 2008; Yu et al., 2008, and associated ACPD online open discussions). Detailed and wellconstrained case studies (Yu and Turco, 2008) indicate that, for most of well-defined nucleation events observed during an intensive field campaign in Hyytiälä, Finland, the predictions based on the IMN model are in good agreement with field data for a range of variables, including critical nucleation sizes, size-dependent overcharging ratios, concentrations of 1.8-3 nm stable clusters and 3-6 nm particles, as well as their diurnal variations. Yu and Turco (2008) concluded that, beyond a reasonable level of uncertainty, IMN appears to be the dominant nucleation mechanism in at least a large fraction of nucleation events observed in boreal forests.

The main objective of the present paper is to study the contribution of IMN mechanism, which has been constrained by a variety of up-to-date thermodynamic data and supported by recent field measurements in boreal forests, to global particle number abundance. To achieve the objective, an advanced particle microphysics (APM) model has been coupled with a global chemistry transport model using assimilated meteorology (GEOS-Chem) to simulate the spatial and temporal variations of particle number size distribution in the global atmosphere. The details of the coupled model and key features are described in Sect. 2. Section 3 presents modeling results and comparisons with measurements. Summary and discussion are given in Sect. 4.

\section{Description of models, approaches, and key features}

\subsection{Advanced Particle Microphysics (APM) model}

The APM model is an advanced multi-type, multicomponent, size-resolved microphysics code developed for a wide range of applications. The current APM model is the result of past development and validation effort aimed at explaining atmospheric particle observations (e.g., Turco et al., 1979; Hamill et al., 1982; Toon et al., 1988; Jacobson et al., 1994; Jacobson and Turco, 1995; Yu and Turco, 1997, 2008; Yu, 1998). The basic microphysical processes that are treated in the model include nucleation, condensation/evaporation, coagulation, thermodynamic equilibrium with local humidity, and dry deposition. In coupling with GEOS-Chem, sizedependent schemes for wet-deposition (washout and rainout) have been implemented. The APM model is very flexible in specifying the number of bins (sections), number of compositions, and number of types of aerosols to be simulated.

The current version of the APM model is highly modularized and formatted as a stand-alone box model. For applications when computing cost is not a limitation, the
APM model can be customized to treat complex and detailed aerosol systems with high size resolution. For example, in the cases of studying particle formation and evolution in aircraft plumes and in ambient atmosphere, the model can distinguish particles with different charging states and compositions (Yu, 1998; Yu and Turco, 1997, 2008) and can resolve liquid and frozen contrail particles formed from particles of different compositions (Yu, 1998; Kärcher and Yu, 2009). In these applications, particles ranging in size from molecular (diameter $\sim 0.6 \mathrm{~nm}$ ) to larger than $10 \mu \mathrm{m}$ are represented by hundreds of sectional bins using a discrete-sectional bin structure, and the size-dependent electrostatic effect on particle microphysics can be considered (Yu, 2006).

To treat size-resolved aerosol microphysics in a 3dimensional model, computing cost becomes a significant limitation. Based on our experience with past applications of the APM model as a box model and our understanding of key processes/parameters controlling aerosol microphysical properties, we have designed and implemented a number of schemes/algorithms that improve the computing efficiency for 3-D application. Pre-calculated look-up tables are extensively used for nucleation rate and coagulation kernel calculations which substantially reduce the computing time. The bin resolution can be variable which means that we can choose high size resolution for a certain size range (of interest) while using low resolution for other size ranges. This enables us to use a reasonable number of bins to cover a wide size range while optimizing size resolution. The model allows the different microphysical processes to be calculated at different time steps and automatically decides the optimum time steps for computing efficiency without sacrificing accuracy.

\subsection{GEOS-Chem model}

The GEOS-Chem model is a global 3-D model of atmospheric composition driven by assimilated meteorological observations from the Goddard Earth Observing System (GEOS) of the NASA Global Modeling Assimilation Office (GMAO). The GEOS-Chem model includes a detailed simulation of tropospheric ozone-NOx-hydrocarbon chemistry as well as of aerosols and their precursors (Park et al., 2004). A detailed description of the model (including the treatment of various emission sources, chemistry and aerosol schemes) can be found in the model webpage (http://acmg.seas.harvard.edu/geos/index.html).

Meteorological factors used in GEOS-Chem include surface properties, humidity, temperature, winds, cloud properties, heat flux and precipitation. The present version of GEOS-Chem (v8-01-03) is fully compatible with the GMAO GEOS-5 operational data product. The GEOS-5 data, including cloud fields, have 6-h temporal resolution (3-hour resolution for surface fields and mixing depths), $0.5^{\circ} \times 0.667^{\circ}$ horizontal resolution, and 72 vertical sigma levels extending from the surface to approximately $0.01 \mathrm{hPa}$. The horizontal 
resolution can be degraded and vertical layers merged for computational efficiency. It is noteworthy that GEOS-5 has a higher vertical resolution in the lower troposphere (14 vertical levels below $2 \mathrm{~km}$ ) than that of GEOS-3 ( 9 levels below $2 \mathrm{~km})$ and GEOS-4 (5 levels below $2 \mathrm{~km}$ ).

In addition to sulfate, nitrate, and ammonium aerosols (Park et al., 2004), the GEOS-Chem model also considers black carbon (BC) and primary organic carbon (POC) (Park et al., 2003), SOA (Park et al., 2003; Liao et al., 2007), dust (Fairlie et al., 2007), and sea salt (Alexander et al., 2005). The mass of dust is separated into four sizes (Fairlie et al., 2007) while that of sea salt is divided into two sizes (Alexander et al., 2005). Aerosol and gas-phase simulations are coupled through secondary inorganic and organic particle formation, heterogeneous chemistry (Evans and Jacob, 2005), and aerosol effects on photolysis rates (Martin et al., 2003). The ISORROPIA thermodynamic equilibrium model (Nenes et al., 1998) is used to calculate partitioning of total ammonia and nitric acid between the gas and aerosol phases, while SOA is produced from the oxidation of biogenic hydrocarbons following the scheme of Chung and Seinfeld (2002) with updates detailed in Liao et al. (2007). The publicly released version of GEOS-Chem (v8-01-03) simulates the mass concentrations of particles of different types or compositions but does not treat size-resolved aerosol microphysics.

\subsection{GEOS-Chem coupled with APM model: key features}

In order to study the spatial and temporal variations of global $\mathrm{CCN}$ abundance, the size-resolved aerosol microphysics has to be handled properly within the global model. We have coupled the APM model with a recently released version of GEOS-Chem (v8-01-03). In the present study, size-resolved microphysics for sulfate and sea salt aerosols is considered. The formation of new particles is calculated with the stateof-the-art ion-mediated nucleation mechanism. The contributions of nitrate, ammonium, and SOAs to sulfate particle growth are considered through equilibrium uptake. The scavenging of sulfate particles by other types of particles (sea salt, BC, POC, and dust) is considered. The emission inventories and parameterizations, as well as key features of the coupled model related to size-resolved aerosol microphysics are described below. The emission discussion focuses on our additions/updates to what have been included in the original GEOS-Chem model.

\subsubsection{Emissions}

\subsubsection{Sulfur emission inventories and parameterization of primary sulfate particle emission}

In this study, the global sulfur emission is based on the Emissions Database for Global Atmospheric Research (EDGAR) inventory (Olivier et al., 2001), while the emissions over
United States, Mexico and East Asia are replaced by the Environmental Protection Agency (EPA/NEI99) inventory, the Big Bend Regional Aerosol and Visibility Observational (BRAVO) Study emissions inventory (Mark et al., 2003), and the Transport and Chemical Evolution over the Pacific (TRACE-P) inventory (Streets et al., 2003), respectively. We have scaled the EDGAR sulfur emission over Europe based on the information presented in Vestreng et al. (2007). Due to the uncertainty of the emissions from sporadically erupting volcanoes, we only consider the continuously active volcano emission.

Most recent global aerosol simulations assume that $0-5 \%$ of anthropogenic sulfur species is emitted as sulfuric acid or sulfate while the rest as $\mathrm{SO}_{2}$ (Adams and Seinfeld, 2002, 2003; Spracklen et al., 2005a; Pierce and Adams, 2006; Pierce et al., 2007; Wang and Penner, 2009). While this fraction of sulfate mass has been called primary sulfate, it is actually secondary in nature because it is used to account for the sub-grid plume scale $\mathrm{SO}_{2}$ oxidation and new particle formation and growth (e.g., Spracklen et al., 2005a). The primary sulfate is generally distributed into two lognormal modes with geometric mean diameters $\left(\mathrm{d}_{g}\right)$ of $10 \mathrm{~nm}$ (nucleation mode) and $70 \mathrm{~nm}$ (accumulation or condensation mode) with standard deviations $(\sigma)$ of 1.6 and 2.0, respectively (Whitby, 1978). All the above mentioned studies cited either Binkowski and Shankar (1995) or Whitby (1978) to assume that $15 \%$ of primary sulfate mass is emitted in the nucleation mode while the rest in the accumulation mode. Actually, it appears that Binkowski and Shankar (1995) also cited the work of Whitby (1978) for the number. However, Whitby (1978), based on the observations presented in Whitby et al. (1978), showed that the fraction of primary sulfate in the nucleation mode is 5\% (instead of widely used $15 \%)$ while the remaining $(95 \%)$ of sulfate (formed in subgrid $\mathrm{SO}_{2}$ plumes) condenses directly onto existing particles.

In the present study, to account for the sub-grid secondary particle formation, we assume that $2.5 \%$ of anthropogenic sulfur is emitted as sulfate (the number suggested in Dentener et al., 2006) and the fractions of the primary sulfate distributed to the nucleation and accumulation modes are 5\% and 95\%, respectively (Whitby et al., 1978). It should be pointed out that $95 \%$ of primary sulfate mass condenses on the existing particles (or accumulation mode particles) and thus doesn't form new particles. In our simulation, this $95 \%$ of primary sulfate mass is added to the sulfate mass associated with BC and POC particles. To look into the effect of sub-grid nucleation, we carry out a sensitive study assuming all anthropogenic sulfur is emitted as $\mathrm{SO}_{2}$.

\subsubsection{Sea salt emission}

In the original version of GEOS-Chem (v8-01-03), sea salt emissions, both of accumulation mode particles (0.1$0.5 \mu \mathrm{m})$ and coarse mode particles $(0.5-10 \mu \mathrm{m})$, are calculated with the parameterization of Gong et al. (1997). In 
the present study, the recent parameterization of Clark et al. (2006) is employed to calculate the size-resolved sea salt emission.

\subsubsection{Emissions of carbonaceous aerosol}

Carbonaceous aerosol emissions mainly result from fossil fuel and bio-fuel combustion, and biomass burning. The default carbonaceous emissions inventory in GEOS-Chem includes anthropogenic emission based on the work of Bond et al. (2004), biofuels based on Yevich and Logan (2003), and biomass emission from GEOS-Chem inventory (Park et al., 2003). The base year of the Bond et al. (2004) emissions is 1996 for fossil fuel and the fire counts during 1999-2000 for biomass burning. The biomass burning carbonaceous aerosol can also use annually averaged inventory (Bond et al., 2004) or monthly averaged emissions from the Global Fire Emissions Database Version 2 (GFED2) biomass burning emissions. In this study, anthropogenic carbonaceous emission used Bond et al. (2004)'s fossil and biofuel inventories, while biomass burning emission is based on GFED2's monthly open fire inventory. Carbonaceous aerosols in GEOS-Chem are divided into hydrophilic and hydrophobic categories. The model assumes that $20 \%$ of black carbon and 50\% of organic carbon from anthropogenic emissions are hydrophilic and the rest are hydrophobic. Conversion of hydrophobic to hydrophilic carbonaceous aerosols takes place with an e-folding time of 1.2 days based on Cooke et al. (1999). The scheme provides a good simulation of soluble species concentrations in the United States (Park et al., 2003; 2004) and in North American and Asian outflow (Li et al., 2005; Park et al., 2005).

In the original version of GEOS-Chem, the emission heights of carbonaceous aerosols, both anthropogenic and biomass burning emissions, are evenly divided into the model boxes within the boundary layer. Observations indicate that biomass burning injects carbonaceous aerosols to high latitudes due to the buoyancy and shallow convection (Dentener et al., 2006). In this study, we parameterize the injection heights according to the fractional distribution of emission heights for wild-land fires described by Dentener et al. (2006).

\subsubsection{Emission of other species}

The size-dependent emission of dust particles is calculated with the dust emission module described in Fairlie et al. (2007). Global ammonia and NOx sources are as described by Park et al. (2006). The emissions of volatile organic compounds are as described in Liao et al. (2007).

\subsubsection{Representation of major particles in the coupled model}

\subsubsection{Sulfate (or secondary) particles}

We use 40 sectional bins to represent sulfate (or secondary) particles covering dry diameters ranging from $0.0012 \mu \mathrm{m}$ to $12 \mu \mathrm{m}$. The first bin of sulfate particles corresponds to the sizes of freshly nucleated particles in the atmosphere which generally have a dry diameter of $\sim 1.2 \mathrm{~nm}$ (Yu and Turco, 2008), therefore no parameterization is needed to scale the nucleated particles to the first bin particles.

Figure 1 shows the bin structure for sulfate particles and the normalized number of particles emitted into each bin $(\Delta \mathrm{Ni} / \Delta \log$ Dpi) per $\mu \mathrm{g}$ of primary sulfate emitted based on the parameterizations described in Sect. 2.3.1.1. The bin structure or width of each bin can be clearly seen from Fig. 1. As mentioned earlier, the bin resolution in the APM model can be variable so we can use a higher resolution for the size range of our interest. The numerical diffusion is generally small when the number of bins per decade of size space is >10 (Jacobson et al., 1994; Yu, 1998). For the GEOSChem-APM coupled model, we have 30 bins for 0.0012 $0.12 \mu \mathrm{m}$ (dry diameter) range and another 10 bins for 0.12 $12 \mu \mathrm{m}$, leaving a high resolution for the size range important to the growth of nucleated particles to $\mathrm{CCN}$ (i.e., $\sim 15$ bins per decade). The variable bin structure enables us to cover full particle size range and have good resolution in the size range important for the study (in the current case nucleation mode and CCN particles) while maintaining a reasonable total number of bins (and hence computing cost).

Based on the two log-normal distributions shown in Fig. 1, per $\mu \mathrm{g}$ of primary sulfate emission adds $2.08 \times 10^{10}$ of particles to the nucleation mode (5\% mass) and $3.55 \times 10^{8}$ of particles to the accumulation mode ( $95 \%$ mass). Our model has the option to treat the accumulation mode sulfate mass as new particles (increase in number concentration) or as mass condensed to the existing particles (no increase in number concentration). As noted in Sect. 2.3.1.1, the sulfate mass in the accumulation mode is the mass condensing on the existing particles and thus doesn't form new particles (i.e., no increase in number concentration). In the present study, this 95\% of primary sulfate mass is added to the sulfate mass associated with primary BC and OC particles. It should also be noted that even those nucleation mode particles, while called primary sulfates, are actually secondary particles associated with sub-grid new particle formation in $\mathrm{SO}_{2}$ plumes.

\subsubsection{Sea salt}

Primary emission is the only source of sea salt particles which generally have dry diameters larger than $\sim 10 \mathrm{~nm}$. Based on our assessment of size-resolved sea salt emission observations and parameterizations (O'Dowd et al., 1997; Clark et al., 2006), sea salt particles with dry diameters 


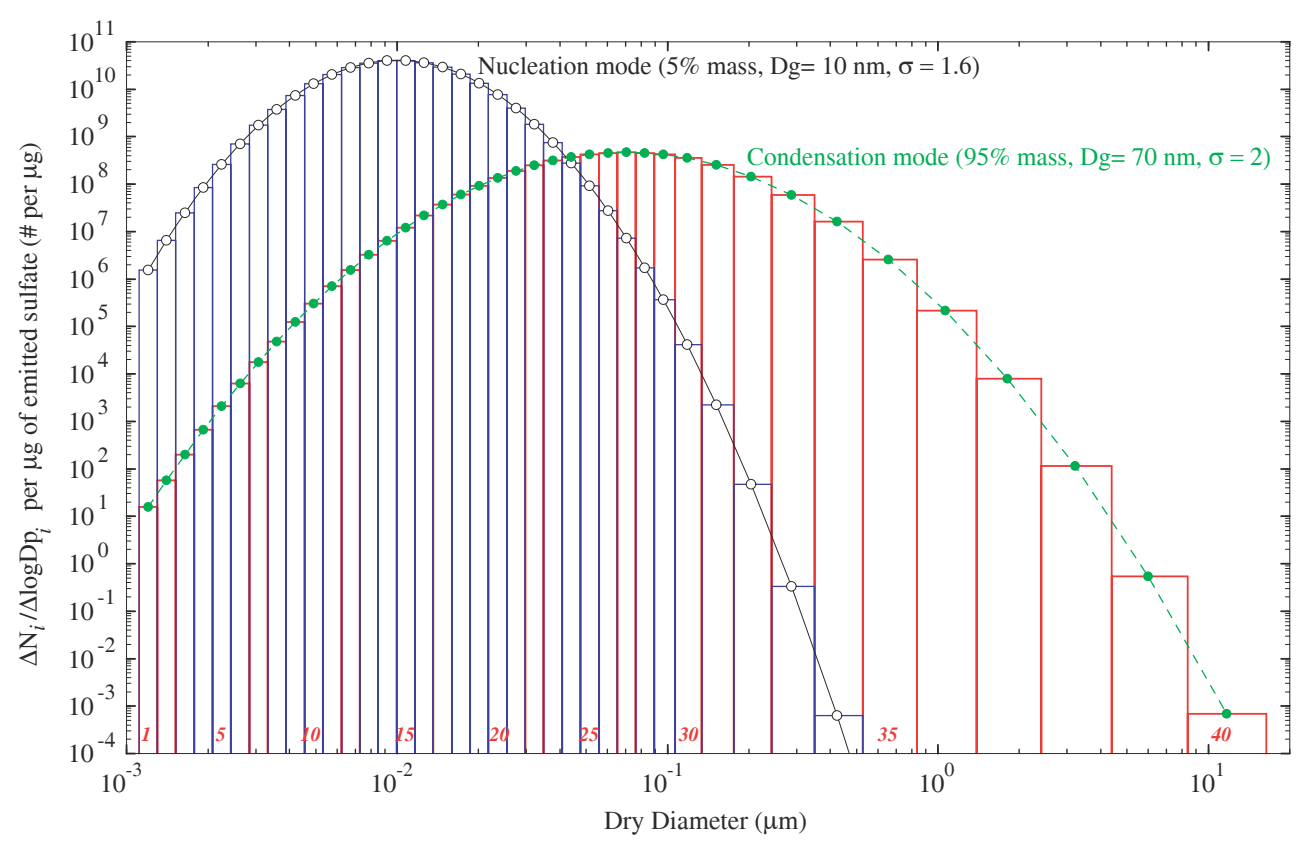

Fig. 1. Bin structure for sulfate particles and normalized number of primary sulfate particles emitted into each bin $\left(\Delta \mathrm{Ni} / \Delta \operatorname{logDp}{ }_{i}\right)$ per $\mu \mathrm{g}$ of sulfate emitted. The bin indices are marked with red numbers in the bottom of the figure. Bin resolution is variable, with 30 bins allocated for $0.0012-0.12 \mu \mathrm{m}$ range (dry diameter) and another 10 bins for $0.12-12 \mu \mathrm{m}$ range. The bin middle sizes are marked with dots and the edges are shown in rectangle columns. The bin structure is chosen to have relatively high resolution for the size range important to the growth of nucleated particles (a few nanometers) to $\mathrm{CCN}$ (dry diameters: $\sim 30-80 \mathrm{~nm}$ ). See text for discussion about the parameterization of primary sulfate emissions.

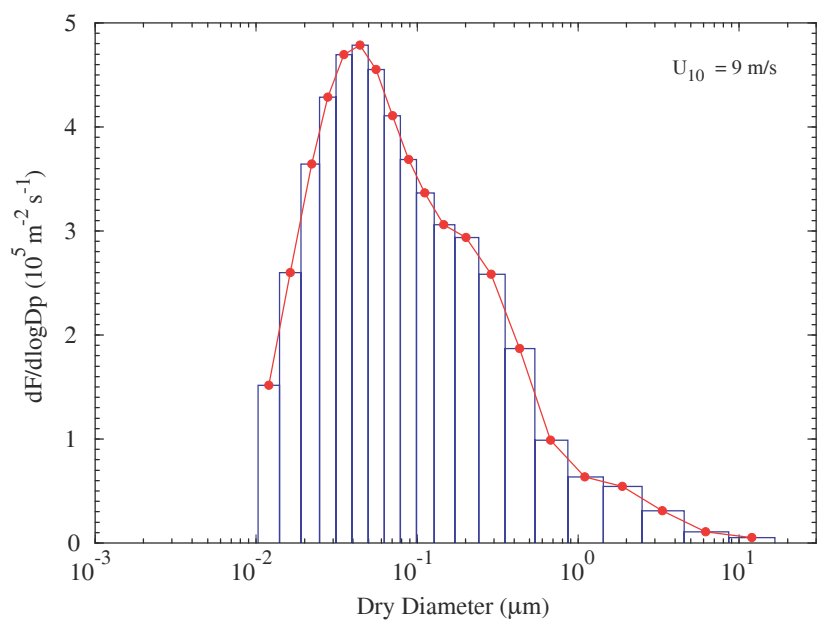

Fig. 2. Bin structure for sea salt particles and the normalized number flux of sea salt particles ( $\mathrm{dF} / \mathrm{dlogdr}$ in $\# \mathrm{~m}^{-2} \mathrm{~s}^{-1}$ ) based on the parameterization of Clarke et al. (2006) with wind speed at a height of $10 \mathrm{~m}\left(\mathrm{U}_{10}\right)=9 \mathrm{~m} / \mathrm{s}$. Bin resolution is variable and 10 bins are used for $0.012-0.12 \mu \mathrm{m}$ (dry diameter) range and another 10 bins for $0.12-12 \mu \mathrm{m}$. The middle sizes are marked with dots and the edges are shown in rectangle columns. The bin structure is chosen to have relatively high resolution for the size range important to the contribution of sea salt to $\mathrm{CCN}$ number abundance. smaller than $\sim 10 \mathrm{~nm}$ are negligible both in term of number and mass concentration, and there is no need to represent small size sea salt particles in the model. In the present study, the size-resolved sea salt emission is based on the parameterization of Clarke et al. (2006). We use 20 sectional bins to represent sea salt, covering dry diameters from 0.012 to $12 \mu \mathrm{m}$. Figure 2 shows bin structure for sea salt and normalized number flux of sea salt particles $\left(\mathrm{dF} / \mathrm{d} \log \mathrm{dr}\right.$ in $\left.\# / \mathrm{m}^{2} \mathrm{~s}\right)$ based on the parameterization of Clarke et al. (2006). The peak in number-based flux is around $\sim 0.045 \mu \mathrm{m}$. Bin resolution is variable and 10 bins are used for $0.012-0.12 \mu \mathrm{m}$ (dry diameter) range and another 10 bins for $0.12-12 \mu \mathrm{m}$. The bin structure is chosen to have relatively high resolution for the size range important to the contribution of sea salt to $\mathrm{CCN}$ number abundance.

\subsubsection{Primary BC and OC (BCOC) particles}

In GEOS-Chem, the total mass of hydrophobic BC, hydrophilic BC, hydrophobic OC, and hydrophilic OC are tracked during the emission, transport, deposition, and scavenging processes. In the present study, we do not implement the size-resolved microphysics for primary BCOC. Primary BCOC particles generally have a log-normal distribution, and we derive the BCOC number concentrations from the simulated mass and assumed size distributions. Existing measurements indicate that the size of BCOC from fossil 
fuel $\left(\mathrm{BCOC}_{F F}\right)$ consumption is quite different from those from biofuel and biomass burning $\left(\mathrm{BCOC}_{B B}\right)$ (Dentener et al., 2006). Dentener et al. (2006) recommended a mode diameter of $30 \mathrm{~nm}$ and standard deviation of 1.8 for $\mathrm{BCOC}_{F F}$, and mode diameter of $80 \mathrm{~nm}$ and standard deviation of 1.8 for $\mathrm{BCOC}_{B B}$. Based on our review of the relevant literature, the mode diameters recommended by Dentener et al. (2006) appear to be much smaller than what have been observed (including the data presented in Fig. $\mathrm{C} 1$ of Dentener et al., 2006). The log-normal mode diameter of $\mathrm{BCOC}_{F F}$ is generally $\sim 60 \mathrm{~nm}$ (Kittelson et al., 2000, 2006; Eastwood, 2007; Weimer et al., 2009) while that of $\mathrm{BCOC}_{B B}$ is $\sim 150 \mathrm{~nm}$ (e.g., Anderson et al., 1996; also see Fig. $\mathrm{C} 1$ in Dentener et al., 2006).

To properly calculate the contribution of BCOC to the number concentration of total particles as well as $\mathrm{CCN}$, we separate $\mathrm{BCOC}$ into two categories (i.e., $\mathrm{BCOC}_{F F}$ and $\mathrm{BCOC}_{B B}$ ) and each category has four tracers (i.e., hydrophobic $\mathrm{BC}$, hydrophilic $\mathrm{BC}$, hydrophobic $\mathrm{OC}$, and hydrophilic OC). In the present study, BCOC $_{F F}$ is assumed to have a lognormal distribution with number median diameter of $60 \mathrm{~nm}$ and standard deviation of 1.8 , and $\mathrm{BCOC}_{B B}$ is assumed to have a log-normal distribution with number median diameter of $150 \mathrm{~nm}$ and standard deviation of 1.8 . We assume that only hydrophilic BC and OC can serve as CCN.

\subsubsection{Secondary organic aerosol (SOA)}

The schemes used to represent and simulate SOA formation in GEOS-Chem have been described in Chung and Seinfeld (2002) and Liao et al. (2007). Monoterpenes and other reactive volatile organic compounds (ORVOCs) are divided into five hydrocarbon classes according to the values of their experimentally measured aerosol yield parameters. The semi-volatile gas phase products from the oxidation of various hydrocarbons (including isoprene) by $\mathrm{OH}, \mathrm{O}_{3}$, and $\mathrm{NO}_{3}$ are lumped into four tracers (SOG1, SOG2, SOG3, and SOG4), and all aerosol phase products are aggregated into four corresponding tracers (SOA1, SOA2, SOA3, and SOA4). The partition of SOGs onto seed aerosols, which include primary organic carbon, sulfate, ammonium, nitrate, and sea salt, is considered in GEOS-Chem.

\subsubsection{Dust}

Dust particles in GEOS-Chem are represented by 4 size sections (diameters: $0.2-2.0,2.0-3.6,3.6-6.0$, and 6.0$12.0 \mu \mathrm{m})$ (Ginoux et al., 2004).

\subsubsection{Sulfate mass scavenged by other types of particles}

While secondary sulfate particles (containing nitrate, ammonium, and SOAs through equilibrium uptake or partition) are ubiquitous in the atmosphere and appear to dominate the number concentrations in many regions, the primary particles (BC, POC, dust, and sea salt) could be important and even dominant in some regions. The scavenging of secondary particles by primary particles is an important process in governing the total particle number concentrations. In order to assess the relative contribution of secondary versus primary particles to CCN budget, the scavenging of secondary particles by primary particles has to be properly considered. In the present study, the coagulation scavenging of secondary sulfate particles by primary particles are simulated using four separate tracers (BC_sulfate, OC_sulfate, sea salt_sulfate, and dust_sulfate) to keep track of the bulk sulfate mass associated with BC, OC, sea salt, and dust, respectively. It should be noted that we add the sulfate mass to primary particles after coagulation even when the sulfate particles are larger than the primary particles, which may lead to the underestimation of the contribution of secondary particles to CCN. In addition to coagulation, condensation (of sulfuric acid) and in-cloud $\mathrm{SO}_{2}$ oxidation also contribute to BC_sulfate, OC_sulfate, sea salt_sulfate, and dust_sulfate. When some of BC, OC, sea salt, and dust are removed from the atmosphere via dry and wet deposition, the corresponding portion of sulfate associated with these particles are also removed. The equilibrium uptake of nitrate, ammonium, and SOAs by the sulfate mass associated with primary particles and the resulting change in the sizes of primary particles are considered in our simulation and CCN calculation. We distribute the sulfate (and associated SOA, nitrate, ammonium) to the bulk populations according to the surface areas of primary particles.

\subsubsection{Key microphysical processes controlling particle size distributions}

\subsubsection{Nucleation}

Nucleation is one of the key process controlling particle number distribution and CCN number abundance. In this study, we focus on the ion-mediated nucleation (IMN) because it is physically-based and constrained by recently available laboratory data (Yu, 2006), can explain most of the nucleation events observed in boreal forests (Yu and Turco, 2008), and predicts global nucleation distributions in reasonable consistency (in terms of both spatial patterns and absolute magnitude) with land-, ship-, and aircraft-based observations (Yu et al., 2008).

As pointed out in the Introduction, several recent studies used the empirical formula to represent boundary layer nucleation while employed binary homogeneous nucleation theory for nucleation calculation above boundary layer (e.g., Spracklen et al., 2008; Makkonen et al., 2009; Wang and Penner, 2009). A major difference of present study is that we apply the same physics-based IMN mechanism to the whole atmosphere. The IMN model takes into account the variations of $\left[\mathrm{H}_{2} \mathrm{SO}_{4}\right]$, temperature, relative humidity, ionization, and surface area of pre-existing particles on global new particle formation. The deterministic physics underlying the IMN mechanism allows the spatial and temporal variations 
of secondary particle formation (via IMN) and its contribution to total particle number concentration and $\mathrm{CCN}$ abundance in the whole atmosphere to be quantified in a consistent way.

For IMN rate calculation, we employ look-up tables pregenerated from detailed kinetic IMN model (Yu, 2009), With a simple multiple-variable interpolation subroutine, IMN in each grid box can be calculated accurately (the error between interpolated and full model values within a few percentage) and efficiently (Yu, 2009).

\subsubsection{Condensation and equilibrium partition}

Existing particles (especially nucleated particles) experience size changes through uptake or desorption of precursor gases. In the present study, the condensation of $\mathrm{H}_{2} \mathrm{SO}_{4}$ on particles is explicitly resolved while the uptake of nitrate, ammonium, and condensable secondary organic compounds are considered through equilibrium partition. The inorganic equilibrium is calculated based on ISOROPIA (Nenes et al., 1998) and organic partition is calculated based on the Chung and Seinfeld (2002)'s scheme. The amounts of nitrate, ammonium, and SOA partitioned to sulfate particles in each bin and sulfate mass associated with primary particles are assumed to be proportional to the corresponding sulfate mass. Therefore, our model takes into account the effect of nitrate, ammonium, and SOA uptake on sulfate particle growth, which is important to assess the contribution of nucleated particles to $\mathrm{CCN}$.

In the current model, secondary particles have three different sizes: the first one is the sulfate core size (i.e., the size of sulfate only, defined in bin structure shown in Fig. 1), the second one is the dry size (sulfate + uptaken equilibrium nitrate, ammonium, and SOA), and the third is the wet size accounting for hygroscopic growth (see Sect. 2.3.3.4). Wet size is used to calculate rates (surface area, condensation sink, coagulation coefficient, deposition rate, and scavenging rate) for microphysical simulations. The particles are moving across bins only when their core sizes change (through $\mathrm{H}_{2} \mathrm{SO}_{4}$ condensation and in-cloud oxidation).

Nucleation and condensation processes compete for sulfuric acid vapor, and a time step of $15 \mathrm{~min}$ is used for the integrated calculations of $\mathrm{H}_{2} \mathrm{SO}_{4}$ vapor production, nucleation, and condensation. Number concentration of particles is conserved during growth.

\subsubsection{Coagulation}

Coagulation is a process in which particles of various sizes and compositions collide with each other and coalesce to form larger particles. In the atmosphere, coagulation is an important process scavenging small particles and turning externally mixed particles into internally mixed particles. In the present model, the mass conserving semi-implicit numerical scheme of Jacobson et al. (1994) is employed to solve the self coagulation of size-resolved sulfate and sea salt particles, as well as the scavenging of sulfate particles by sea salt, dust, $\mathrm{BC}$, and POC particles.

Coagulation is the most time-consuming process among various size-resolved microphysical processes (nucleation, growth, coagulation, and deposition). The reason is that coagulation involves particles of different sizes and thus adds two additional dimensions (size of particle $\mathrm{A}$ and size of particle B) into 3-dimensional spatial grid system. For example, for 40 bins of sulfate, coagulation among sulfate particles is equivalent to solving $40 \times 40=1600$ reaction equations. In contrast, growth and deposition processes are 1dimensional in particle size space thus only need to solve 40 equations for size-resolved sulfate particles. The interactions among particles of different types or compositions also add to the number of equations to be solved. For example, the interaction of 40-bin sulfate with 20-bin sea salt will add $40 \times 20=800$ equations. To reduce the computing cost of 3-D sectional aerosol microphysics model, it is important to optimize the coagulation calculation. In the APM model, we have implemented two schemes which substantially reduce the coagulation computing expenses. The first scheme is to use pre-generated lookup tables for coagulation kernel calculations and the second one is to use a variable time-step for coagulation calculations (Yu, 1998).

\subsubsection{Hygroscopic growth, gravitational settling, and dry deposition}

Hygroscopic growth of particles are calculated based on growth factor parameterizations of Li et al. (2001) for inorganic components, of Varutbangkul et al. (2006) for SOA, and of Gerber (1985) for sea salt. With these parameterizations, we can obtain the wet size of different particles for the simulations of various microphysical processes. The size-dependent gravitational settling velocities are based on the scheme given in Zhang et al. (2001). Dry deposition of aerosols in GEOS-CHEM is calculated using the updated resistance-in-series approach of Wesely (1989).

\subsubsection{Wet deposition and cloud processing}

Wet deposition in GEOS-Chem, as described in Liu et al. (2001), includes scavenging in convective updrafts, rainout and washout from convective anvils and large-scale precipitation, and returning to the atmosphere following evaporation. Below we discuss our modifications to the wet deposition scheme, aimed to take advantage of the additional tracers treated in the coupled model.

For size-resolved sulfate and sea salt particles, we assume that particles larger than the activation diameter are subjected to removal via in-cloud scavenging (rainout). The activation diameters for large-scale $(0.19 \%$ supersaturation) and convective precipitation $(0.75 \%$ supersaturation $)$ are assumed to be $0.082 \mu \mathrm{m}$ and $0.032 \mu \mathrm{m}$ (dry diameter), respectively 
(Trivitayanurak et al., 2008). Scavenging in convective updrafts is also limited to those activated particles (dry diameter larger than $0.032 \mu \mathrm{m}$ ). We calculate the removal rate of sulfate and sea salt particles by falling rain droplets using the size-resolved washout rate parameterization developed by Henzing et al. (2006), which calculates precipitation scavenging coefficients as a function of aerosol particle size and precipitation intensity.

The production of sulfate via in-cloud chemistry includes reactions with both hydrogen peroxide and ozone (Park et al., 2004). We distribute sulfate mass produced by in-cloud aqueous oxidation to particles of different types (including sea salt, BC, POC, and dust particles) or bins (for sulfate particles) according to the corresponding number concentrations of activated particles. Aqueous chemistry in stratiform and convective clouds is not distinguished in GEOS-Chem. Following the approach of Trivitayanurak et al. (2008), we distribute sulfate produced by in-cloud aqueous oxidation to those particles with dry diameter larger than $0.057 \mu \mathrm{m}$ (an average of aerosol activation diameters in stratiform and convective clouds).

\subsubsection{Computing cost of the GEOS-Chem-APM model}

In our study, all simulations are running on 8-CPU Linux workstations with the $2.2 \mathrm{Ghz}$ Dual Quad-Core AMD Opteron Processor 2354. The model system is compiled using OpenMP (http://www.openmp.org) for running in parallel. The original GEOS-Chem v8-01-03 code has 54 tracers, and it takes $24.23 \mathrm{~h}$ for one year full-chemistry simulations at $4^{\circ} \times 5^{\circ}$ horizontal resolutions and 47 layers (GEOS-5 data). The coupled GEOS-Chem-APM model has 127 tracers (73 additional tracers: 40 for sulfate, 20 for sea salt, one for $\mathrm{H}_{2} \mathrm{SO}_{4}$ gas, 4 tracers for BC/OC from fossil fuel, 4 tracers for $\mathrm{BC} / \mathrm{OC}$ from biomass/bio-fuel, and 4 for sulfate attached to dust, BC, primary OC, and sea salt particles). With full sizeresolved microphysics (nucleation, condensation, coagulation, deposition, and scavenging) and chemistry, it takes the coupled model (127 tracers) $52.35 \mathrm{~h}$ for the same year simulations on the same machine. In other words, our efficient microphysics schemes allow the increase in the computing cost per $100 \%$ increase in number of tracers (associated with particle size information) to $(52.35 / 24.23-1) /(127 / 54-1)=86 \%$. Such a relatively small increase in the computing cost associated with full size-resolved microphysics is desirable and makes the future coupling of APM model with global climate model feasible.

\section{Results}

The results presented in this section are based on one year (2006) simulation of GEOS-Chem (version 8-01-03 with a horizontal resolution of $4^{\circ} \times 5^{\circ}$ and 47 layers up to $0.01 \mathrm{hpa}$, GEOS-5 meteorological fields) coupled with the
APM model. The original GEOS-Chem model (54 tracers) was spun up for one year and then the coupled model (127 tracers) was spun up for two additional months. All the results presented in the manuscript have not been normalized to standard condition (1 atm, 298K).

\subsection{Spatial distributions of aerosol number concentra- tions: simulation and comparison with measure- ments}

Number concentrations of atmospheric particles have been measured in many parts of globe, and a number of stations have continuous and long-term (multiple-year) measurements. To compare simulated results with observations, we compiled a list of surface observations that have at least one full year of particle number concentration measurements. We limit the measurements to those taken outside urban areas because the present simulation is not designed to resolve the urban scale pollution. Table 1 summarizes mean concentrations of condensation nuclei larger than $10 \mathrm{~nm}$ (CN10) from various sources which we have found to date and the corresponding station information. While GEOS-Chem uses sigma coordinates, it cannot resolve some sub-grid topographies because of its horizontal resolution. Among the 22 stations used in this study, three of them are considered to sample middle tropospheric air based on their elevation and location.

Figure 3 presents the simulated horizontal spatial distributions of annual mean number concentrations of $\mathrm{CN} 10$ averaged within two altitude ranges: (a) Lower boundary layer $(0-0.4 \mathrm{~km})$, and (b) Middle troposphere $(2-4 \mathrm{~km})$. The fraction of anthropogenic sulfur emitted as sulfate is assumed to be $2.5 \%$. The observed annual or multiple-year averaged CN10 values given in Table 1 are also overlaid on the plots for comparison.

It is clear from Fig. 3a that high concentrations of CN10 in the boundary layer are generally confined to regions with large anthropogenic emissions. Annual mean CN10 can reach above $10000 \mathrm{~cm}^{-3}$ in certain areas of United States and China. Over large area of Europe, annual mean CN10 is over $3000 \mathrm{~cm}^{-3}$ with largest value reaches $\sim 8000 \mathrm{~cm}^{-3}$. In the marine boundary layer (MBL) far from anthropogenic sources, CN10 is generally below $700 \mathrm{~cm}^{-3}$ and can be as low as $\sim 200 \mathrm{~cm}^{-3}$. Antarctic and Arctic boundary layer has the lowest $\mathrm{CN} 10$ with values around a few hundreds per $\mathrm{cm}^{3}$.

Figure $3 b$ indicates that $\mathrm{CN} 10$ concentrations in the middle troposphere $(2-4 \mathrm{~km})$ are much lower and the high concentration regions no longer have a clear association with anthropogenic source regions except in a few locations. CN10 values in the $2-4 \mathrm{~km}$ altitude ranges are relatively high in the tropic and sub-tropic regions $\left(30^{\circ} \mathrm{S}-45^{\circ} \mathrm{N}\right)$ with the annual mean values in the range of $\sim 400-700 \mathrm{~cm}^{-3}$. Similar to the boundary layer, $\mathrm{CN} 10$ values in the middle troposphere over Arctic regions are lowest (below $\sim 200 \mathrm{~cm}^{-3}$ ). 
Table 1. Mean concentrations of condensation nuclei with diameter larger than $10 \mathrm{~nm}$ (CN10) measured in 22 surface stations around the globe. Based on the elevation and location of stations, the data are organized as measurements in the boundary layer and in the middle troposphere. The stations are ordered according to the descending latitude.

\begin{tabular}{|c|c|c|c|c|c|c|c|}
\hline $\begin{array}{l}\text { Station } \\
\text { number }\end{array}$ & Location or Station Name & $\begin{array}{l}\text { Period of data } \\
\text { used for average }\end{array}$ & $\begin{array}{l}\text { Latitude } \\
\text { (degree) }\end{array}$ & $\begin{array}{r}\text { Longitude } \\
\text { (degree) }\end{array}$ & $\begin{array}{l}\text { Elev. } \\
(\mathrm{m})\end{array}$ & $\begin{array}{l}\mathrm{CN} 10 \\
\left(\mathrm{~cm}^{-3}\right)\end{array}$ & $\begin{array}{l}\text { Source } \\
\text { of data }\end{array}$ \\
\hline \multicolumn{8}{|c|}{ Boundary Layer } \\
\hline 1 & Point Barrow, AK, USA & 2000-2006 & 71.32 & -156.6 & 11 & 231 & A \\
\hline 2 & Pallas-Sammaltunturi, Finland & 1997-2004 & 67.97 & 24.12 & 560 & 802 & A \\
\hline 3 & Värriö, Finland & 1998-2006 & 67.77 & 29.58 & 400 & 823 & $\mathrm{~B}$ \\
\hline 4 & Hyytiälä, Finland & 1996-2006 & 61.85 & 24.28 & 180 & 2016 & $\mathrm{~B}$ \\
\hline 5 & Uto, Baltic Sea & March 2003-December 2006 & 59.78 & 21.38 & 8 & 2921 & $\mathrm{~B}$ \\
\hline 6 & Aspvreten, Sweden & June 2000-December 2006 & 58.77 & 17.4 & 25 & 2567 & $\mathrm{~B}$ \\
\hline 7 & Mace Head, Ireland & 1991-1994 & 53.33 & -9.9 & 5 & 1907 & A \\
\hline 8 & Melpitz, Germany & January 2006-December 2006 & 51.5 & 12.9 & 86 & 4664 & $\mathrm{C}$ \\
\hline 9 & Sable Island, NS, Canada & 1993-1996 & 43.9 & -60 & 5 & 869 & $\mathrm{D}$ \\
\hline 10 & Thompson Farm, NH, USA & 2001-2005 & 43.11 & -70.95 & 75 & 7039 & $\mathrm{~F}$ \\
\hline 11 & Trinidad Head, California & $2003-2006$ & 41.05 & -124.2 & 107 & 918 & A \\
\hline 12 & Bondville, IL, USA & 2000-2006 & 40.1 & -88.3 & 230 & 5038 & A \\
\hline 13 & Southern Great Plains, OK, USA & $2000-2006$ & 36.8 & -97.5 & 314 & 5064 & A \\
\hline 14 & American Samoa, USA & 1994-1996 & -14.24 & -170.6 & 42 & 270 & A \\
\hline 15 & Botsalano game reserve, S. Africa & July 2006-June 2007 & -25.54 & 25.75 & 1424 & 2340 & G \\
\hline 16 & Bago State forest, Australia & July 2005-October 2006 & -35.66 & 148.15 & 1200 & 1800 & $\mathrm{H}$ \\
\hline 17 & Cape Grim, Australia & 2000-2006 & -40.68 & 144.69 & 94 & 1203 & A \\
\hline 18 & Neumayer, Antarctica & 2000-2006 & -70.65 & -8.25 & 42 & 324 & A \\
\hline 19 & South Pole, Antarctica & $1991-1998$ & -89.98 & -24.8 & 2810 & 156 & A \\
\hline \multicolumn{8}{|c|}{ Middle troposphere } \\
\hline 20 & Jungfraujoch, Switzerland & 1996-2006 & 47.6 & 8 & 3580 & 803 & A \\
\hline 21 & Pyramid, Nepal & March 2006-August 2007 & 27.96 & 86.82 & 5079 & 900 & I \\
\hline 22 & Mauna Loa, HI, USA & 2000-2006 & 19.54 & -155.6 & 3397 & 360 & A \\
\hline
\end{tabular}

Source of CN10 data: A (World Data Centre for Aerosols, http://wdca.jrc.ec.europa.eu); B (Dal Maso et al., 2008); C (CREATE Aerosol Database at NILU, http://tarantula.nilu.no/projects/ccc/create/index.htm); D (NOAA ESRL/GMD Aerosol Database, http://www.cmdl.noaa. gov/aero); F (Ziemba et al., 2006); G (Laakso et al., 2008); H (Suni et al., 2008); I (Venzac et al., 2008).

A comparison of our simulated spatial distribution of annual mean $\mathrm{CN} 10$ in the lower boundary layer $(0-0.4 \mathrm{~km})$ and middle troposphere $(2-4 \mathrm{~km})$ with those measured values show very good agreement in nearly all 22 sites. The simulations capture the absolute values of observed CN10 as well as the spatial gradient quite well. For example, the simulations show a significant CN10 gradient from north to south in Western Europe, with annual mean CN10 values increase from $\sim 700 \mathrm{~cm}^{-3}$ at latitude of $\sim 70^{\circ} \mathrm{N}$ to $\sim 7000 \mathrm{~cm}^{-3}$ at latitude of $\sim 50^{\circ} \mathrm{N}$. Such a dramatic spatial gradient agrees well with observations made in Pallas, Värriö, Hyytiälä, Uto, Aspvreten, and Melpitz. The nice agreement between simulated values of CN10 in the middle troposphere with those obtained at three high altitude stations gives us additional confidence on the ability of the model simulating the vertical distributions of particle number abundance.

For the simulations shown in Fig. 3, we assume that $2.5 \%$ of anthropogenic sulfur emits as primary sulfate $\left(\mathrm{f}_{\text {sulfate }}=2.5 \%\right)$ and $5 \%$ of these mass is distributed to the nucleation mode while the remaining $95 \%$ is added to the con- densation mode. As we pointed out in Sect. 2.3.1.1, such a parameterization of primary sulfate may have large uncertainty. To assess the effect of primary sulfate emission, we carry out a sensitivity study with $\mathrm{f}_{\text {sulfate }}=0$. Figure 4 shows the simulated horizontal spatial distributions of annual mean number concentrations of $\mathrm{CN} 10$ averaged in the lower boundary layer $(0-0.4 \mathrm{~km})$ for $\mathrm{f}_{\text {sulfate }}=0$ case, similar to Fig. 3a with observed data points included. The corresponding figure for the middle troposphere is not shown because of minor differences with Fig. 3b.

A comparison of Fig. 4 with Fig. 3a indicates that primary sulfate emission has substantial impact on the CN10 values in the anthropogenic sulfur source regions (especially in East Asia, Western Europe, and Eastern United States), increasing the CN10 by $\sim 10-40 \%$. Primary sulfate emission, aimed to take into account sub-grid nucleation process in anthropogenic $\mathrm{SO}_{2}$ plumes, has minor effect on the $\mathrm{CN} 10$ budget in areas away from the source regions (including oceans, remote continental area, and air above boundary layer). 

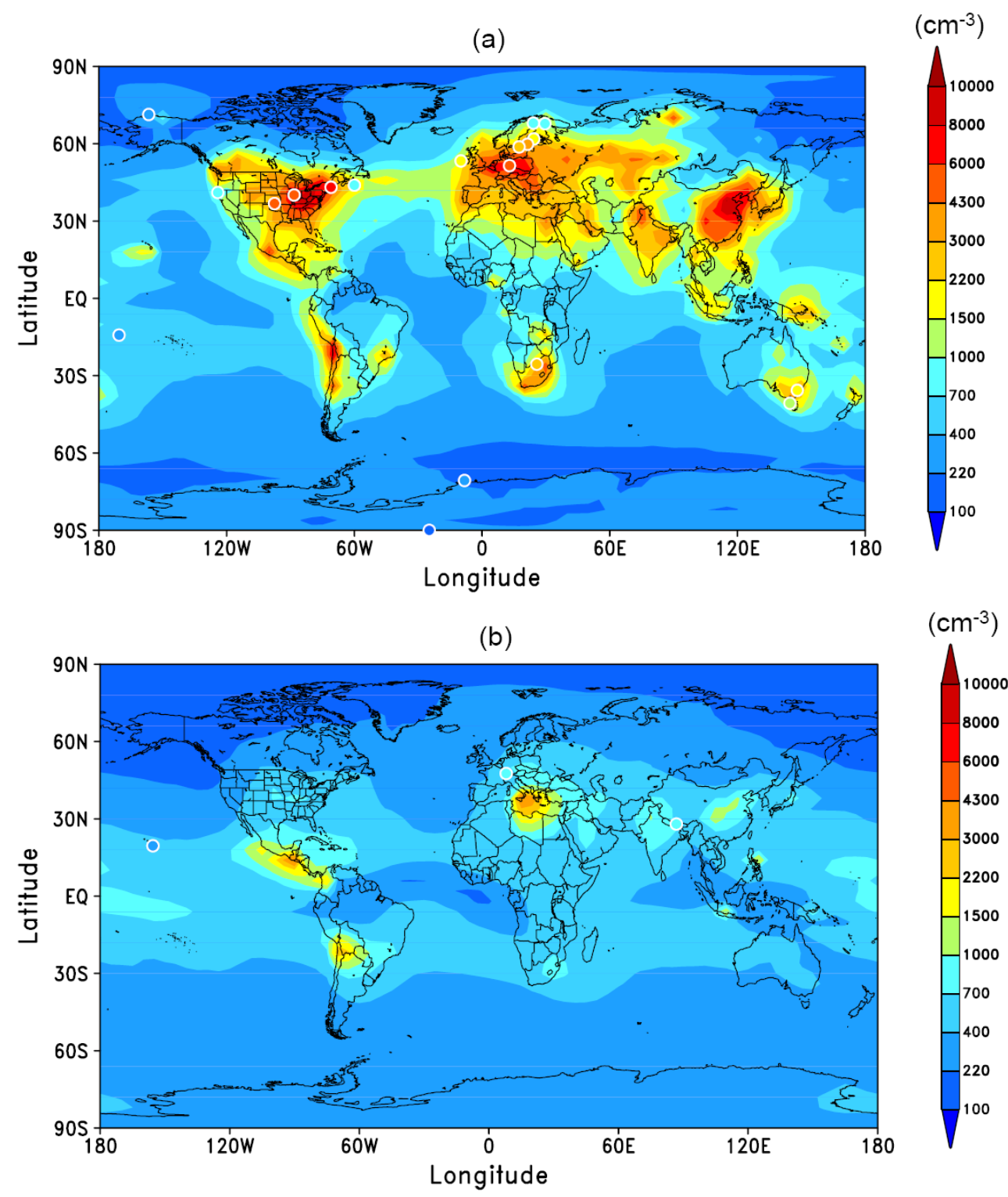

Fig. 3. Simulated horizontal spatial distributions of annual mean number concentrations of particles larger than $10 \mathrm{~nm}(\mathrm{CN} 10)$ averaged within two altitude ranges: (a) Lower boundary layer $(0-0.4 \mathrm{~km})$, (b) Middle troposphere $(2-4 \mathrm{~km})$. The observed annual or multiple year averaged CN10 values given in Table 1 are also overlapped on the plots for comparison. $2.5 \%$ of anthropogenic sulfur is assumed to be emitted as sulfate.

A more specific comparison of simulated $\mathrm{CN} 10$ with observed values is presented in Fig. 5 where the simulated values are plotted against corresponding observed values at 22 sites listed in Table 1. As shown in Fig. 3, the simulated annual mean $\mathrm{CN} 10$ values agree quite well with observed ones, within a factor of two for all the sites except one. The simulated CN10 at South Great Plains (station \# 13 in Table 1) is $\sim 40 \%$ of the observed annual mean value, indicating that the current model under-predicts the new particle formation (or primary particle emission) in the region. The exact reason of such a substantial under-prediction remains to be investigated.
Figure 5 further shows that the emission of $2.5 \%$ of anthropogenic sulfur as primary sulfate has minor effects for sites far away from source regions but can increase the annual mean $\mathrm{CN} 10$ by around $10-40 \%$ in or near source regions. Inclusion of a few percentage of primary sulfate emission, aimed to take into account the sub-grid scale nucleation, appears to improve the agreements of simulated CN10 with observed values in high anthropogenic sulfur source regions such as in Western Europe and Eastern United States. The remaining paper will focus on the case with $\mathrm{f}_{\text {sulfate }}=2.5 \%$. 


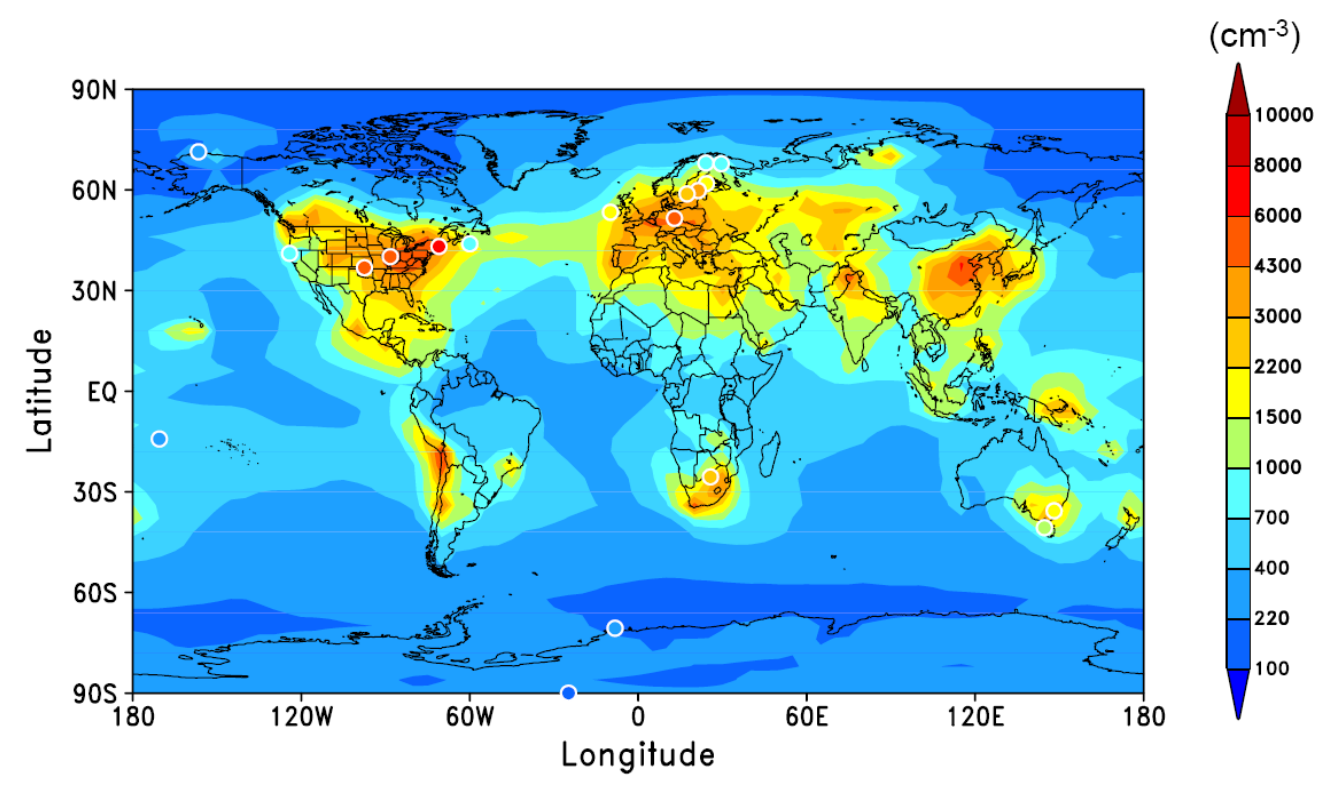

Fig. 4. Same as Fig. 3a except with no primary sulfate emission.

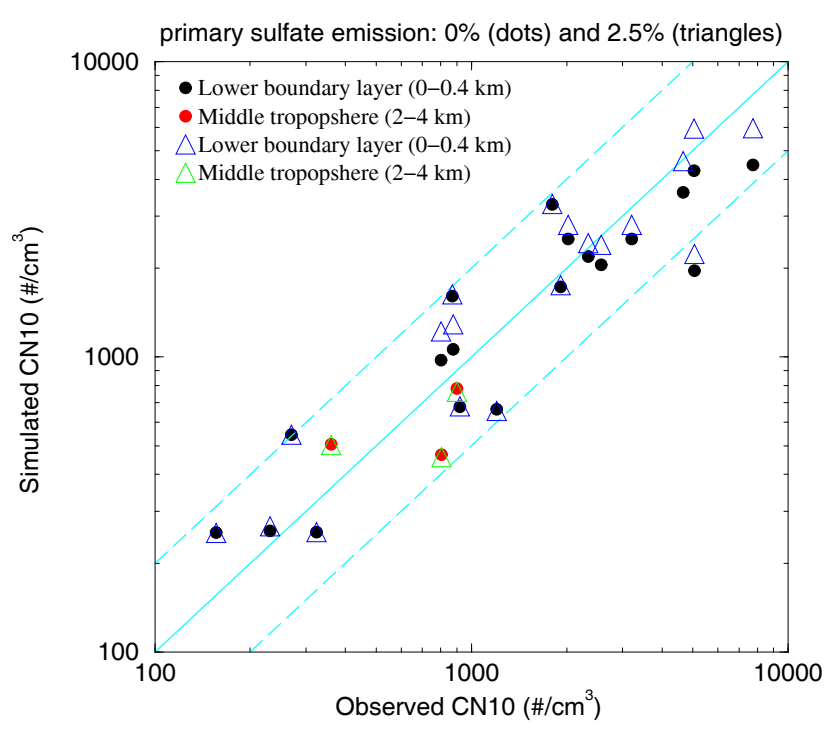

Fig. 5. Comparison of simulated and observed annually averaged number concentrations of condensation nuclei larger than $10 \mathrm{~nm}$ (CN10) at 22 sites listed in Table 1. The solid line shows a 1:1 ratio and the dashed lines show ratios of 2:1 and 1:2. Filled circles are for the case with no primary sulfate emission (i.e., $\mathrm{f}_{\text {sulfate }}=0$ ) and unfilled triangles are for the case with $2.5 \%$ of anthropogenic sulfur emitted as sulfate (i.e., $\mathrm{f}_{\text {sulfate }}=2.5 \%$ ). The symbols in black and blue denote the sites in lower boundary layer $(0-0.4 \mathrm{~km})$ while those in red and green denote values in middle troposphere $(2-4 \mathrm{~km})$.

\subsection{Relative contribution of secondary versus primary particles to total aerosol number abundance}

We showed in Sect. 3.1 that our model simulations agree well with observed number concentrations of particles larger than $10 \mathrm{~nm}$. Both formation of secondary particles (i.e., nucleation) and direct emission of primary particles contribute to atmospheric particle number abundance. It will be interesting to understand the role of new particle formation in particle number budget in different parts of the globe.

Figure 6 presents the simulated horizontal (averaged in three lowest model layers representing the lower boundary layer) and vertical (zonal-averaged) spatial distributions of annual mean ion-mediated nucleation rate $\left(\mathrm{J}_{\mathrm{IMN}}\right)$, total number concentration of condensation nuclei larger than $3 \mathrm{~nm}$ $(\mathrm{CN} 3)$, and the fraction of $\mathrm{CN} 3$ that is secondary $\left(f_{\mathrm{CN} 3}^{\mathrm{sec}}\right)$. The spatial distribution of $\mathrm{J}_{\mathrm{IMN}}$ in the boundary layer (Fig. 6a) is generally consistent with our previous study (Yu et al., 2008), showing that ion-mediated nucleation in the boundary layer (in consistent with a number of land and ship based nucleation measurements, Yu et al., 2008) is largely confined to two broad latitude belts $\left(\sim 20^{\circ} \mathrm{N}-70^{\circ} \mathrm{N}, \sim 30^{\circ} \mathrm{S}-\right.$ $90^{\circ} \mathrm{S}$ ) and nucleation rates over continentals are generally much higher than those in MBL. Vertically we've seen significant $\mathrm{J}_{\mathrm{IMN}}$ differences between the present and previous studies in the upper troposphere. Figure $3 \mathrm{~b}$ shows that the high $\mathrm{J}_{\mathrm{IMN}}$ values located in the tropical upper troposphere between $400-200 \mathrm{mb}$, with peak annual mean values of $\sim 0.1-0.2 \mathrm{~cm}^{-3} \mathrm{~s}^{-1}$. In the previous study that didn't consider size-resolved microphysics (Yu et al., 2008), the peak $\mathrm{J}_{\text {IMN }}$ exceeds $1 \mathrm{~cm}^{-3} \mathrm{~s}^{-1}$ in the tropic regions above $200 \mathrm{mb}$, which is most likely associated with the under-prediction of 
(a)

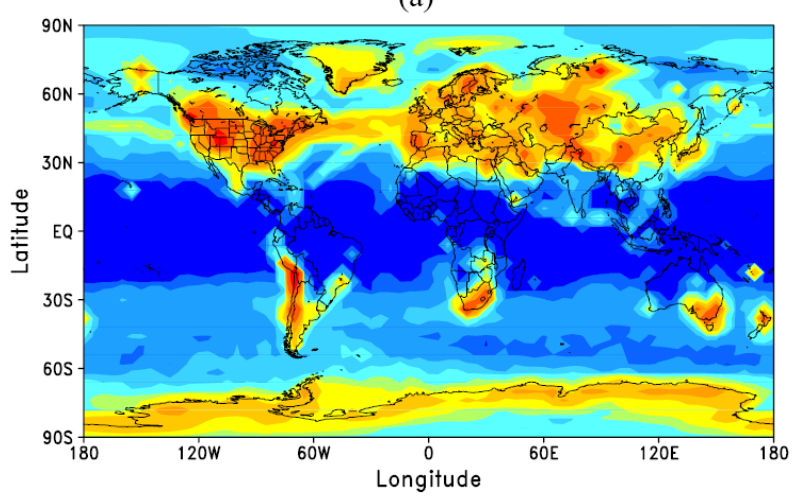

(c)

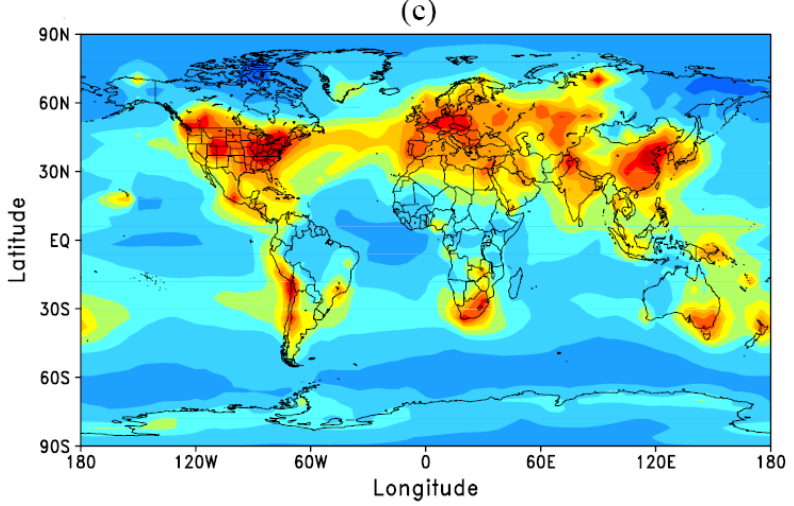

(e)

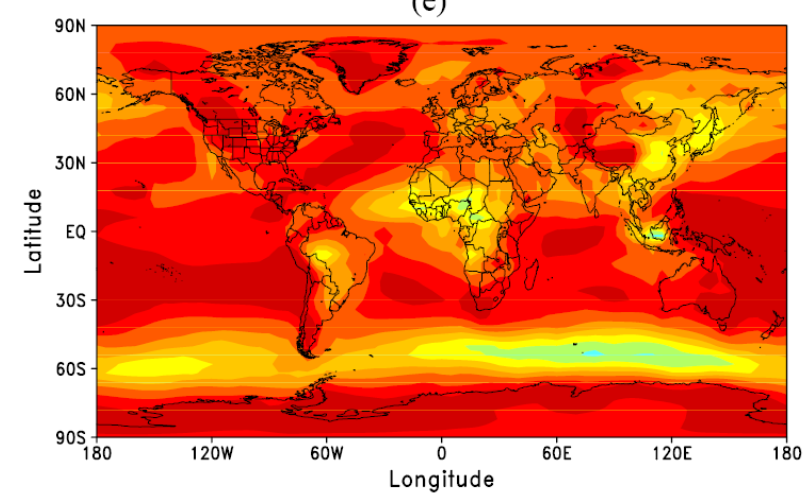

$\left(\mathrm{cm}^{-3} \mathrm{~s}^{-1}\right)$
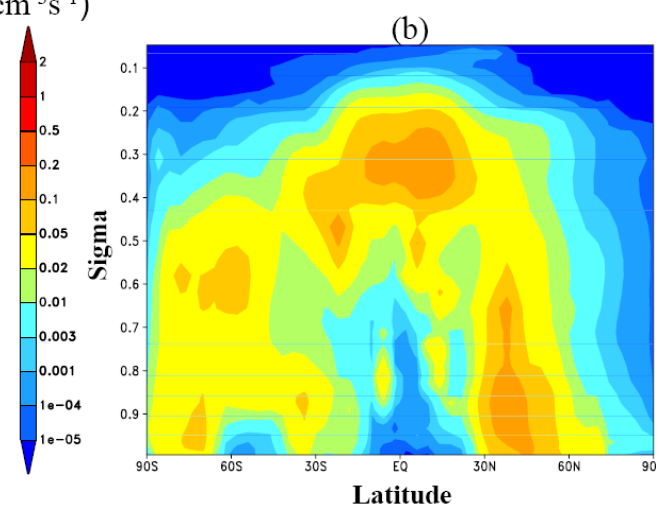

$\left(\mathrm{cm}^{-3}\right)$

$A_{10000}$

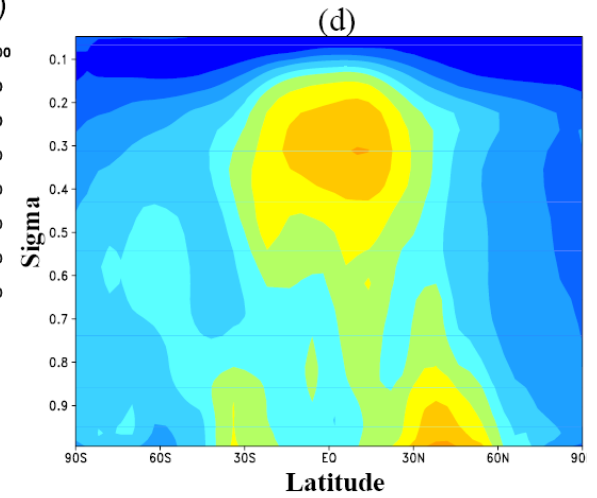

(f)

$(\%)$
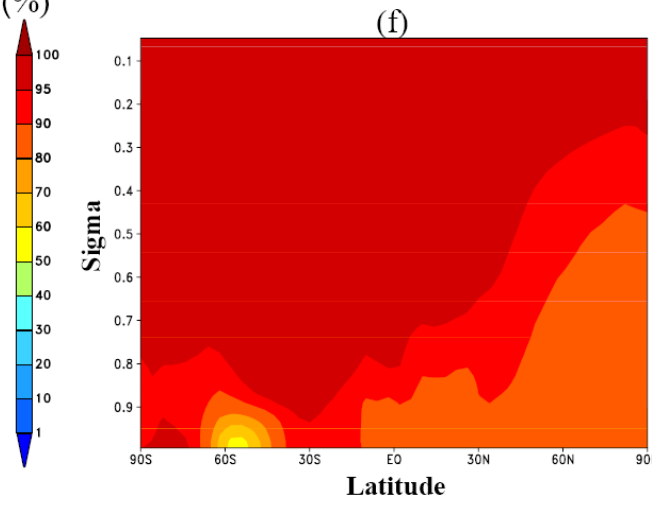

Fig. 6. Horizontal ((a), (c), (e): average over first three model layers above Earth's surface) and vertical ((b), (d), (f): sigma=pressure/surface pressure) distributions of annual mean values of ion-mediated nucleation rate $\left(\mathrm{J}_{\mathrm{IMN}}\right)$, total concentration of particle larger than $3 \mathrm{~nm}(\mathrm{CN} 3)$, and fraction of $\mathrm{CN} 3$ that is secondary.

condensation sink and over-prediction of $\mathrm{H}_{2} \mathrm{SO}_{4}$ vapor concentrations in the tropical upper troposphere.

The spatial distribution of CN3 (Fig. 6c-6d) depends not only on new particle formation rates (Fig. 6a-6b) but also on primary particle emissions, particle transport and scavenging processes. Figure $6 \mathrm{c}$ and $6 \mathrm{~d}$ indicate that the regions with high $\mathrm{CN} 3$ values are generally associated with high nucleation zones but it is also clear that transport, scavenging, and primary emission have substantial impact on $\mathrm{CN} 3$ values in some regions. For example, in tropical MBL, while nucleation is negligible, transport results in an annual mean CN3 values of $200-1000 \mathrm{~cm}^{-3}$. The vertical gradient in CN3 over tropic regions (Fig. 6d) confirms the downward transport of particles formed in the upper troposphere. Primary particle emissions also add substantial amounts of particle numbers in East Asia and Western Europe. The low CN3 zone (around $60^{\circ} \mathrm{S}$ ) in the Southern Ocean BL is due to the scavenging of nucleated particles by sea salt particles. Vertically, there are two regions of high zonally-averaged annual mean CN3 (Fig. 6d): one in the tropical upper troposphere 
(a) Hyytiälä $(61.85 \mathrm{~N}, 24.28 \mathrm{E})$

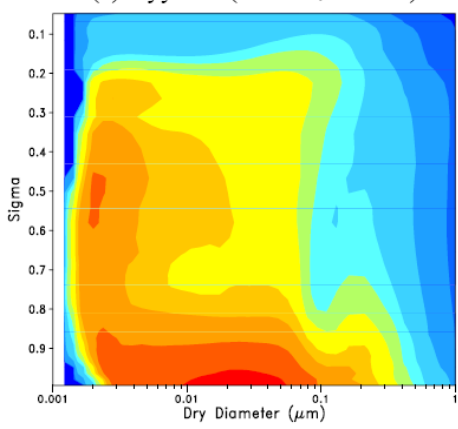

(d) Samoa $(14.24 \mathrm{~S}, 170.57 \mathrm{~W})$

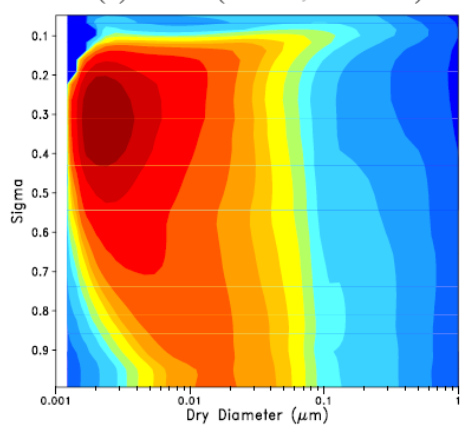

(b) Melpitz $(51.5 \mathrm{~N}, 12.9 \mathrm{E})$

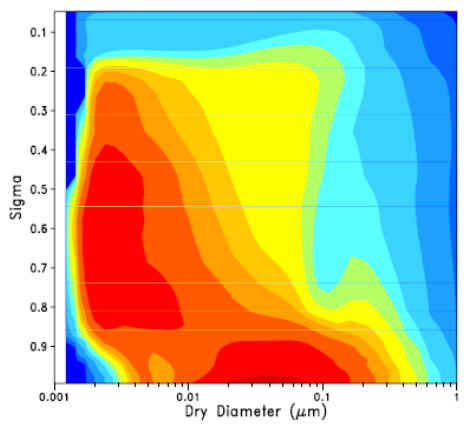

(e) Batsalano (25.54S, 25.75E)

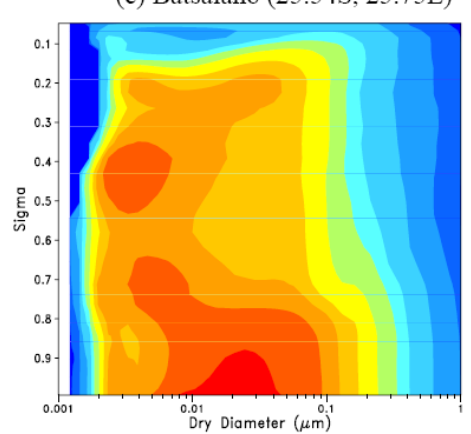

(c) Bondville $(40.1 \mathrm{~N}, 88.3 \mathrm{~W}) \quad \mathrm{dN} / \mathrm{dlog} \mathrm{O}_{\mathrm{p}}$

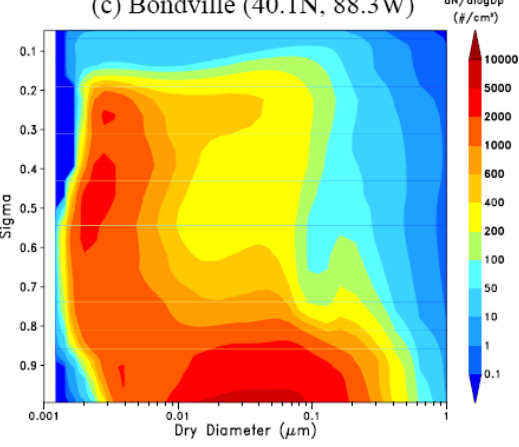

(f) South Pole $(89.98 \mathrm{~S}, 24.8 \mathrm{~W}) \quad$ an/dogop

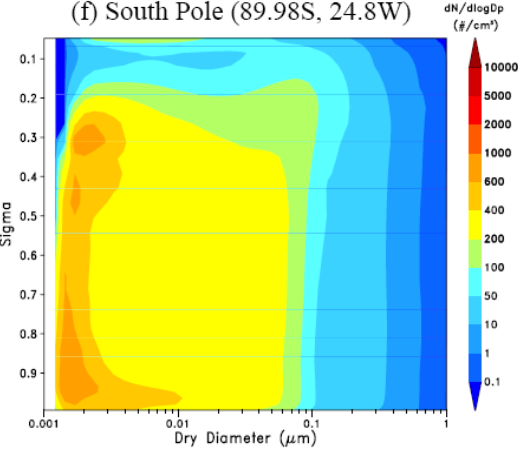

Fig. 7. Simulated annual mean vertical profiles of secondary particle number size distributions at six of the surface measurement sites listed in Table 1 .

and the other in the middle latitude lower troposphere in the Northern Hemisphere. Such a feature is generally consistent with the latitudinal and vertical distributions of total condensation nuclei concentrations measured during a number of air-borne field campaigns covering a wide range of areas and seasons (see Fig. 3b in Yu et al., 2008). It should be noted that data in Fig. 3b of Yu et al. (2008) have been normalized to standard condition (1 atm, 298K) while the simulated values in Fig. 6d have not been normalized.

The present model explicitly resolves secondary particles and primary particles as well as their interactions (Sect. 2.3), enabling us to study the relative contribution of secondary particles versus primary particles to total particle number concentrations. The secondary fractions of $\mathrm{CN} 3\left(f_{\mathrm{CN} 3}^{\mathrm{sec}}\right)$ as shown in Fig. 6e-6f indicate that secondary particles dominate the number abundance in most part of the troposphere. Vertically, $f_{\mathrm{CN} 3}^{\mathrm{sec}}$ is generally above $80 \%$, with a large part of the troposphere (especially the Southern Hemisphere) has $f_{\mathrm{CN} 3}^{\mathrm{sec}}$ above $90 \%$. In the lower boundary layer $(0-0.4 \mathrm{~km})$, $f_{\mathrm{CN} 3}^{\mathrm{sec}}$ is generally above $80 \%$ over most part of oceans, North America, Australia, Arctic, and Antarctica, but has relatively lower values of $\sim 50 \%-80 \%$ over South and East Asian, West Europe, West Africa, central South America, and the Southern Ocean. These regions with low $f_{\mathrm{CN} 3}^{\mathrm{sec}}$ are associated with areas of large primary particle emissions and the enhanced scavenging of secondary particles by primary particles.

\subsection{Simulated particle size distributions}

The present GEOS-Chem-APM model has size-resolved microphysics for secondary particles (sulfate particles with uptaken nitrate, ammonium, and SOAs) and primary sea salt particles. Figure 7 presents simulated annual mean vertical profiles of secondary particle number size distributions at three sites in the Northern Hemisphere and another three sites in the Southern Hemisphere (corresponding to stations $4,8,12,14,15$, and 19 listed in Table 1). The dry diameters include the contribution of uptaken nitrate, ammonium, and SOAs. The vertical profiles of secondary particle number distributions over Hyytiälä, Melpitz, Bondville, and Batsalano clearly show a much higher concentration of Aitken particles (dry diameter $0.01-0.1 \mu \mathrm{m}$ ) in the lower troposphere (altitude $<\sim 2 \mathrm{~km}$, or sigma $>\sim 0.8$ ). This is likely due to relatively high nucleation rates in the areas coupled with large concentrations of precursors and growth rate of nucleated particles. Nucleation mode particles (dry diameter $<10 \mathrm{~nm}$ ) appear in nearly all altitudes at all the selected sites except for Samoa where no nucleation mode particles appear in the BL. For the six vertical profiles shown in Fig. 7, the highest particle number concentration appears in the upper troposphere over Samoa located in the tropical Pacific. The decrease in number concentration and the increase in the mean size of nucleated particles strongly suggest the downward transport of particles formed aloft and growth of these 

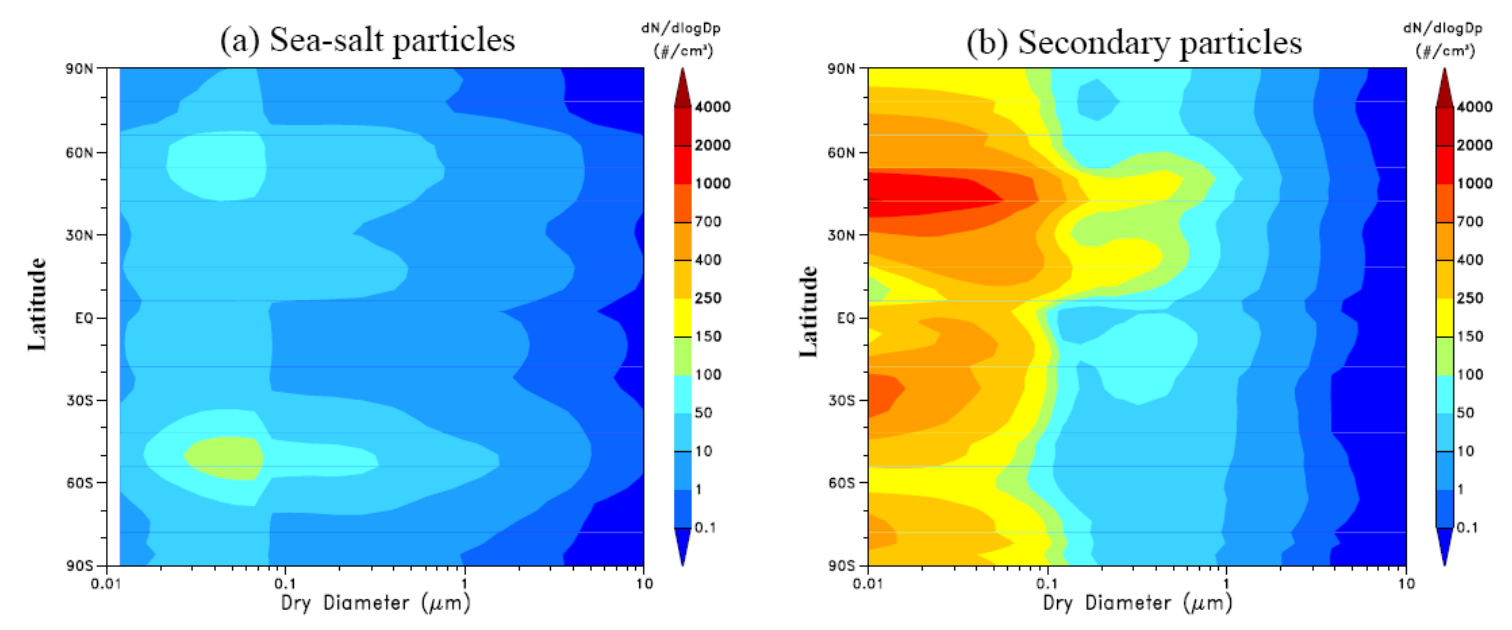

Fig. 8. Meridional distributions of (a) sea salt and (b) secondary particle number size distributions in the Atlantic MBL (0-0.4 km) at longitude of $30^{\circ} \mathrm{W}$.

particles during descent in the tropical regions. While most secondary particles are smaller than $0.1 \mu \mathrm{m}$, we do see that a substantial fraction of nucleated particles can grow to the size range that can act as $\mathrm{CCN}(\sim 0.03-0.08 \mu \mathrm{m}$, depending on the water supersaturation).

Figure 8 shows secondary particle and primary sea salt particle number size distributions in the Atlantic MBL at different latitudes along the line of longitude $=30^{\circ} \mathrm{W}$. Sulfate particles generally dominate the number concentration except around $60^{\circ} \mathrm{S}$ over the Southern Ocean. The ultrafine mode of sea salt can be clearly seen. Secondary particles appear to have bi-modal structure, one Aitken mode smaller than $0.1 \mu \mathrm{m}$ and another accumulation mode larger than $0.1 \mu \mathrm{m}$. There exist two zones of high secondary particle concentration over the Pacific $\sim 30^{\circ} \mathrm{S}$ and $45^{\circ} \mathrm{N}$ which are associated with transport of pollutants from the continents (also see Fig. 6c).

\subsection{Global spatial distribution of $\mathrm{CCN}$ concentration and the contribution of secondary particles}

In the real atmosphere, the number of aerosols activated to become cloud droplets depends on particle size distribution, composition, and water vapor supersaturation (S), and thus is expected to have significant spatial and temporal variations. Based on the simulated size distributions of secondary particles and sea salt particles in addition to assumed sizes of other primary particles (BC, OC, and dust), we can calculate the spatial distribution of $\mathrm{CCN}$ concentration at a given supersaturation. Figure 9 show the predicted $\mathrm{CCN}$ concentration at $\mathrm{S}=0.4 \%$ (CCNO.4) and the fraction of secondary particle $\mathrm{CCN}\left(f_{\mathrm{CCN}}^{\mathrm{sec}}\right)$ in the boundary layer $(0-$ $1 \mathrm{~km})$. Corresponding zonal average vertical profiles are shown in Fig. 10. $\mathrm{S}=0.4 \%$, representing an average $\mathrm{S}$ in the atmosphere, is chosen here because many CCN mea- surements gave $\mathrm{CCN}$ at $\mathrm{S}=0.4 \%$ (Andreae, 2009). Similar horizontal and vertical distributions of $\mathrm{CCN}$ concentrations and $f_{\mathrm{CCN}}^{\mathrm{sec}}$ at $\mathrm{S}=0.2 \%$ and $\mathrm{S}=0.8 \%$ are given in the Supplementary Material http://www.atmos-chem-phys.net/9/7691/ 2009/acp-9-7691-2009-supplement.pdf.

Similar to the spatial distribution of total aerosol number concentrations (Figs. 3 and 6c), high $\mathrm{CCN}$ regions in the lower troposphere are generally confined to main continents. The highest value of CCNO.4 in the BL locates in East Asia, with peak concentration exceeding $2000 \mathrm{~cm}^{-3}$. CCN0.4 in the BL over Eastern United States and a large part of Europe has values above $700 \mathrm{~cm}^{-3}$. In the MBL, CCNO.4 is much lower with lowest CCNO.4 values of below $40 \mathrm{~cm}^{-3}$ located in South Pacific $\left(\sim 30^{\circ} \mathrm{S}\right)$. Over the tropical MBL away from continental influence, CCNO.4 is generally below $70 \mathrm{~cm}^{-3}$. The band of relatively high CCN0.4 over the Southern Ocean MBL (around $60^{\circ} \mathrm{S}$ ) is a result of high sea salt emission associated with strong wind. CCN0.4 in the BL of North Atlantic is above $100 \mathrm{~cm}^{-3}$ which is a factor $\sim 2$ higher than those in remote MBL, indicating a substantial impact of anthropogenic emission on $\mathrm{CCN}$ in the region (also see Fig. 8). Our present simulations indicate that annual mean CCN0.4 values in the Antarctic BL are below $40 \mathrm{~cm}^{-3}$ while those in the Arctic BL are in the range of $70-100 \mathrm{~cm}^{-3}$. Our simulated CCN0.4 distributions are generally consistent with CCNO.4 observations compiled by Andreae (2009), although most of $\mathrm{CCN}$ measurements only lasted for a short period of time. This study focuses on annual mean values. Comparisons of simulated CCN0.4 with those observed at the specific month or season will be the subject of future research.

The fraction of CCNO.4 in the BL that is secondary $\left(f_{\mathrm{CCN}}^{\mathrm{sec}}\right)$ has large spatial variations. As expected, $f_{\mathrm{CCN}}^{\mathrm{sec}}$ has similar horizontal spatial pattern as that of $f_{\mathrm{CN} 3}^{\mathrm{sec}}$ (Fig. 6c) but is a factor of $\sim 1.5$ smaller than $f_{\mathrm{CN} 3}^{\mathrm{sec}}$. Generally more than $60 \%$ of CCN0.4 in the BL over the tropical oceans, Antarctica, 
(a)

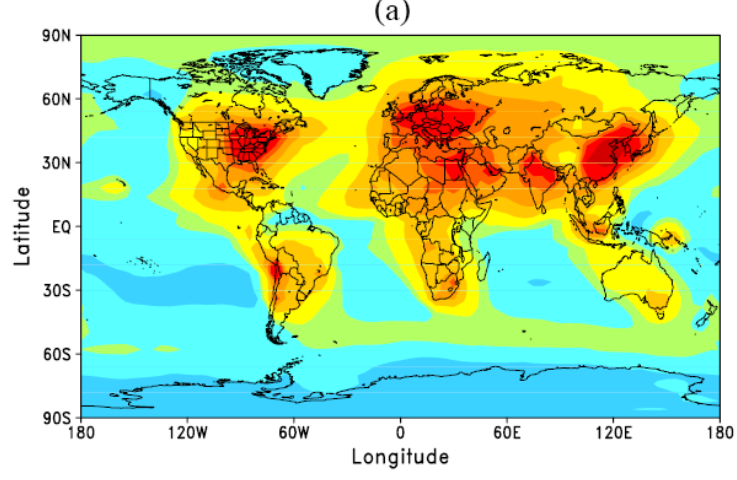

(b)

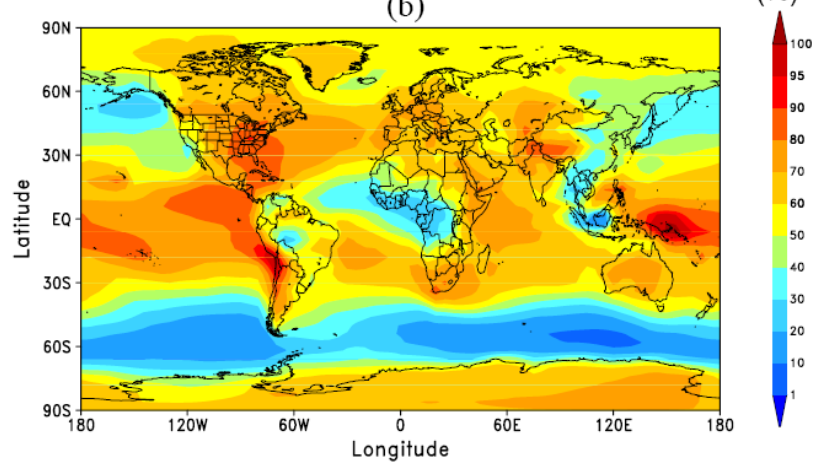

Fig. 9. Predicted annual mean $\mathrm{CCN}$ concentration at supersaturation of $0.4 \%$ (CCN0.4) and the fraction of CCN0.4 that is secondary $\left(f_{\mathrm{CCN}}^{\mathrm{sec}}\right)$ in the boundary layer $(0-1 \mathrm{~km})$.

Eastern United States, Europe, and North Atlantic are secondary. $f_{\mathrm{CCN}}^{\mathrm{sec}}$ is between $20 \%-60 \%$ in the BL of South America, West Africa, East and South Asia, and the associated continental outflow regions. $f_{\mathrm{CCN}}^{\mathrm{sec}}$ has lowest values of below 20\% in the Southern Ocean BL due to large predicted sea salt emissions in the region.

Vertically, CCN0.4 generally decreases with increasing altitudes while $f_{\mathrm{CCN}}^{\mathrm{sec}}$ increases with increasing altitudes (Fig. 10). Over the middle latitude in the Northern Hemisphere, zonally averaged CCN0.4 decreases from $\sim 400$ $700 \mathrm{~cm}^{-3}$ in the BL to below $100 \mathrm{~cm}^{-3}$ above altitude of $\sim 4 \mathrm{~km}$ (sigma $\sim 0.6$ ), and the corresponding $f_{\mathrm{CCN}}^{\mathrm{sec}}$ values change from $50-60 \%$ to above $\sim 70 \%$. It is interesting to note that CCNO.4 has relatively lower values $\left(20-40 \mathrm{~cm}^{-3}\right)$ in the middle and upper troposphere over the tropical regions although the region contains the highest concentration of ultrafine particles (Fig. 6d). In the Southern Hemisphere, the zonally averaged CCN0.4 is below $200 \mathrm{~cm}^{-3}$ and $f_{\mathrm{CCN}}^{\mathrm{sec}}$ is generally above $60 \%$ except in the Southern Ocean BL.

It should be noted that CCN shown in Figs. 910 are for $\mathrm{S}=0.4 \%$. $\mathrm{CCN}$ concentrations and $f_{\mathrm{CCN}}^{\mathrm{sec}}$ will generally increase with increasing $\mathrm{S}$ because secondary particles become more dominant at smaller (a)

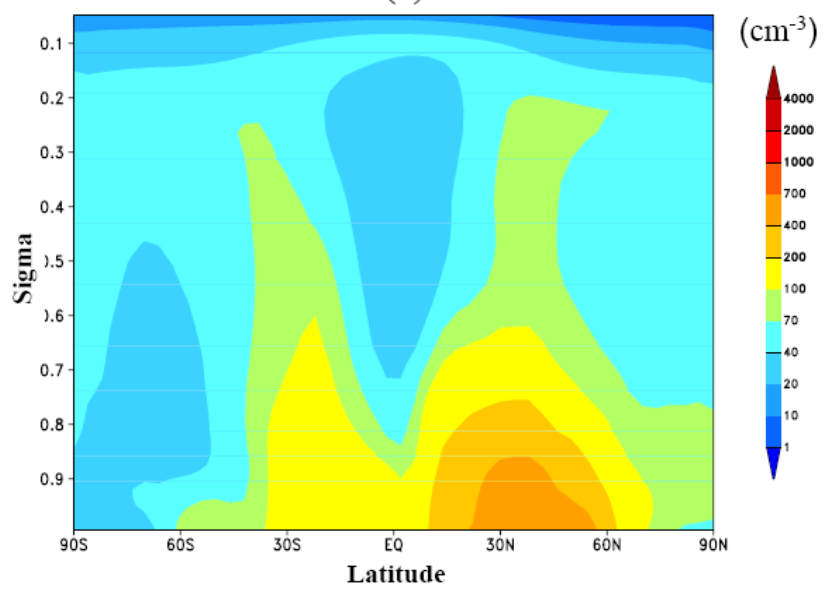

(b)

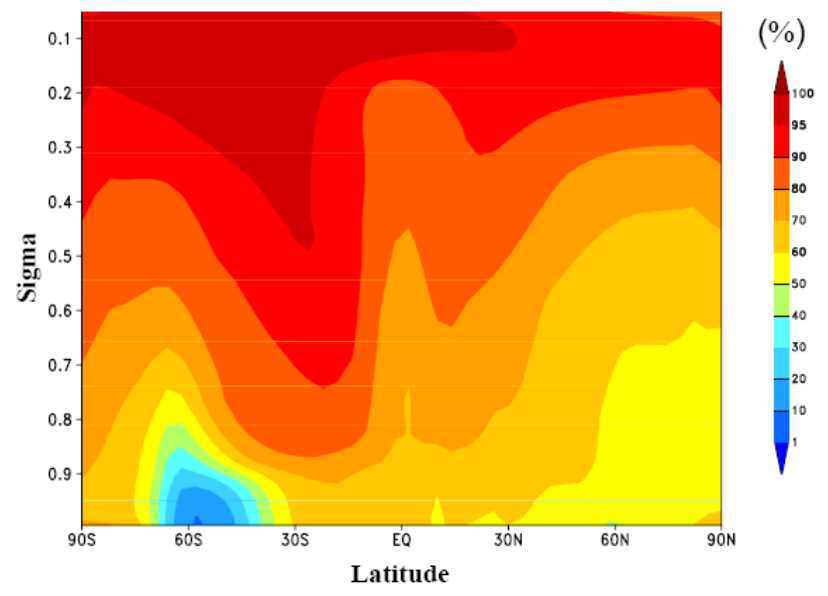

Fig. 10. Zonally-averaged latitudinal and vertical distributions of annual mean values of CCN0.4 and $f_{\mathrm{CCN}}^{\mathrm{sec}}$.

sizes (Fig. 6, also see Figs. S1-S2 in the Supplementary Material http://www.atmos-chem-phys.net/9/7691/ 2009/acp-9-7691-2009-supplement.pdf). As can be expected, our simulated spatial distributions of $\mathrm{CCN}$ concentrations and $f_{\mathrm{CCN}}^{\mathrm{sec}}$ are subject to uncertainties because of the uncertainties in the calculations of nucleation rates and the parameterizations of primary particles as well as other chemical and microphysical processes. Comparisons with $\mathrm{CCN}$ measurements and other observed aerosol properties (for example, the fraction of particles containing refractive cores) will help to identify and reduce the uncertainties.

\section{Summary and discussion}

The magnitude of the aerosol indirect radiative forcing (IRF) represents the dominant uncertainty in assessing climate change. A number of previous studies emphasize the importance of representing size-resolved particle microphysics in 
global models and reducing uncertainties in the sources (nucleation and emission) of atmospheric particles. In this study, an advanced particle microphysics (APM) model has been incorporated into a global chemistry transport model (GEOSChem) to simulate the number size distribution of tropospheric particles, focusing on the contribution of secondary particles to total aerosol number and $\mathrm{CCN}$ abundance.

We use 40 sectional bins to represent sulfate particles and 20 bins to represent sea salt, with higher bin resolution in the size range important for $\mathrm{CCN}$ calculation. The growth of nucleated sulfate particles through the condensation of sulfuric acid vapor and equilibrium uptake of nitrate, ammonium, and SOAs is explicitly simulated in the coupled model. The present model does not treat the size-resolved microphysics for BC, primary OC (POC), and dust. Nevertheless, the scavenging of secondary sulfate particles by primary particles (dust, BC, POC, and sea salt) is considered. BC and POC particles from fossil fuel are separated from those associated with open fire and bio-fuel because of the large differences in the emission height and the sizes of BC and POC particles from these two different sources.

We calculate new particles formation based on the stateof-the-art ion-mediated nucleation (IMN) model and constrain the primary particle emissions with various measurements. Based on our simulations, the annual mean number concentrations of tropospheric particles have clear spatial patterns and vary from a few hundreds per $\mathrm{cm}^{3}$ to more than 10000 per $\mathrm{cm}^{3}$. Zones of high particle number concentration are generally confined to regions with large anthropogenic emissions in the boundary layer but shift to tropical regions in the upper troposphere, which is consistent with many in-situ observations. A comparison of our simulated annual mean concentrations of condensation nuclei larger than $10 \mathrm{~nm}(\mathrm{CN} 10)$ with those measured values show very good agreement in near all 22 sites around the globe that have at least one full year of CN10 measurements. The simulations capture the absolute values of observed CN10 (within a factor of two) as well as the spatial gradient quite well.

Our simulations indicate that secondary particles formed via IMN appear to be able to account for the particle number concentrations observed in many parts of the troposphere. The emission of $2.5 \%$ of anthropogenic sulfur as primary sulfate (aimed to take into account the sub-grid scale nucleation) has minor effect on total particle number concentration in the regions remote from source regions but can increase the annual mean CN10 by around $10-40 \%$ in or near source regions. Secondary particles appear to dominate the number abundance in most parts of the troposphere $(>\sim 80 \%)$, especially over oceans and above the boundary layer over land (> $\sim 90 \%$ ). Primary particles can contribute up to $\sim 20-50 \%$ of total particle numbers in and near strong source regions.

The simulated particle number distributions indicate that, while most of secondary particle are smaller than $0.1 \mu \mathrm{m}$, a non-trivial fraction of nucleated particles can grow to the size range that can act as $\mathrm{CCN}$. Calculated $\mathrm{CCN}$ concentra- tion at supersaturation of $0.4 \%$ (CCN0.4) and the fraction of CCN0.4 that is secondary $\left(f_{\mathrm{CCN}}^{\mathrm{sec}}\right)$ have large spatial variations. Generally more than $60 \%$ of CCN0.4 in the BL over the tropical oceans, Antarctica, the Eastern United States, Europe, and the North Atlantic are secondary. $f_{\mathrm{CCN}}^{\mathrm{sec}}$ is between $20 \%-60 \%$ in the BL of South America, West Africa, East and South Asia, and the associated continental outflow regions. In the Southern Hemisphere, the zonally averaged CCN0.4 is $<200 \mathrm{~cm}^{-3}$ and $f_{\mathrm{CCN}}^{\mathrm{sec}}$ is generally above $60 \%$ except in the Southern Ocean BL. Over the middle latitudes in the Northern Hemisphere, zonally averaged CCNO.4 decreases from $\sim 400-700 \mathrm{~cm}^{-3}$ in the BL to below $100 \mathrm{~cm}^{-3}$ above altitudes of $\sim 4 \mathrm{~km}$, the corresponding $f_{\mathrm{CCN}}^{\mathrm{sec}}$ values change from $50-60 \%$ to above $\sim 70 \%$.

The present study shows the importance of secondary particles in the global total aerosol and CCN budget. While we attempt to use state-of-art nucleation mechanisms and constrain the primary particle emissions with as many observations as possible, the present study is subject to uncertainties and further research are clearly needed to assess the model performance and reduce uncertainty. Additionally, the size-resolved microphysics for BC, POC, and dust are not treated in the present model. In our future study, we will further improve the GEOS-Chem-APM model and carry out a more comprehensive evaluation of the model performance by comparing simulated results with various relevant measures (including size distribution and composition data and their seasonal variations, $\mathrm{CCN}$ measurements, etc.). We will also assess how the uncertainties in the parameterizations of primary particle emissions and nucleation rate calculations may affect conclusions about the relative contribution of secondary and primary particles to global $\mathrm{CCN}$ abundance in different parts of the troposphere.

Acknowledgements. This study is supported by NASA under grant NNX08AK48G, NSF under grant 0618124, and the NOAA/DOC under grant NA05OAR4310103. The GEOS-Chem model is managed by the Atmospheric Chemistry Modeling Group at Harvard University with support from the NASA Atmospheric Chemistry Modeling and Analysis Program.

Edited by: K. Lehtinen

\section{References}

Adams, P. J. and Seinfeld, J. H.: Disproportionate impact of particulate emissions on global cloud condensation nuclei concentrations, Geophys. Res. Lett., 30, 1239, doi:10.1029/2002GL016303, 2003.

Adams, P. J. and Seinfeld, J. H.: Predicting global aerosol size distributions in general circulation models, J. Geophys. Res., 107, 4370, doi:10.1029/2001JD001010, 2002.

Albrecht, B. A.: Aerosols, cloud microphysics and fractional cloudiness, Sciences, 245, 1227-1230, 1989. 
Alexander, B., Park, R. J., Jacob, D. J., Li, Q. B., Yantosca, R. M., Savarino, J., Lee, C. C. W., and Thiemens, M. H.: Sulfate formation in sea salt aerosols: Constraints from oxygen isotopes, J. Geophys. Res., 110, D10307, doi:10.1029/2004JD005659, 2005.

Anderson, B., Grant W., Gregory, G., et al.: Aerosols from biomass burning over the South Atlantic region: Distributions and Impacts, J. Geophys. Res., 101, 24 117-24 138, 1996.

Andreae, M. O.: Correlation between cloud condensation nuclei concentration and aerosol optical thickness in remote and polluted regions, Atmos. Chem. Phys., 9, 543-556, 2009, http://www.atmos-chem-phys.net/9/543/2009/.

Binkowski, F. S. and Shankar, U.: The regional particulate matter model, 1, Model description and preliminary results, J. Geophys. Res., 100, 26 191-26 209, 1995.

Bond, T. C., Streets, D. G., Yarber, K. F., Nelson, S. M., Woo, J.H., and Klimont, Z.: A technology-based global inventory of black and organic carbon emissions from combustion, J. Geophys. Res., 109, D14203, doi:10.1029/2003JD003697, 2004.

Charlson, R. J., Schwartz, S. E., Hales, J. M., Cess, R. D., Coakley, J. A. J., Hansen, J. E., and Hofmann, D. J.: Climate forcing by anthropogenic aerosols, Science, 255, 423-430, 1992.

Chin, M., Kahn, R. A., and Schwart, S. E. (Eds.): Atmospheric Aerosol Properties and Climate Impacts, A Report by the U.S. Climate Change Science Program and the Subcommittee on Global Change Research, National Aeronautics and Space Administration, Washington, D.C., USA, 2009.

Chung, S. H., and Seinfeld, J. H.: Global distribution and climate forcing of carbonaceous aerosols, J. Geophys. Res., 107, 4407, doi:10.1029/2001JD001397, 2002.

Clarke, A. D., Owens, S. R., and Zhou, J. C.: An ultrafine sea salt flux from breaking waves: Implications for cloud condensation nuclei in the remote marine atmosphere, J. Geophys. Res., 111, D06202, doi:10.1029/2005JD006565, 2006.

Cooke, W. F., Liousse, C., Cachier, H., and Feichter, J.: Construction of a $1^{\circ} \times 1^{\circ}$ fossil fuel emission data set for carbonaceous aerosol and implementation and radiative impact in the ECHAM4 model, J. Geophys. Res., 104, 22 137-22 162, 1999.

Dal Maso, M., Hyvarinen, A., Komppula, M., et al.: Annual and interannual variation in boreal forest aerosol particle number and volume concentration and their connection to particle formation, Tellus B, 60B, 495-508, 2008.

Dentener, F., Kinne, S., Bond, T., et al.: Emissions of primary aerosol and precursor gases in the years 2000 and 1750 prescribed data-sets for AeroCom, Atmos. Chem. Phys., 6, 43214344, 2006

http://www.atmos-chem-phys.net/6/4321/2006/.

Eastwood, P.: Particulate Emissions from Vehicles, SBN 0470724552, John Wiley and Sons, 2008

Evans, M. J., and Jacob, D. J.: Impact of new laboratory studies of $\mathrm{N}_{2} \mathrm{O}_{5}$ hydrolysis on global model budgets of tropospheric nitrogen oxides, ozone, and OH, Geophys. Res. Lett., 32, L09813, doi:10.1029/2005GL022469, 2005.

Fairlie, D. T., Jacob, D. J., and Park, R. J.: The impact of transpacific transport of mineral dust in the United States, Atmos. Environ., 41, 1251-1266, 2007.

Gagné, S., Laakso, L., Petäjä, T., Kerminen, V.-m., and Kulmala, M.: Analysis of one year of Ion-DMPS data from the SMEAR II station, Finland, Tellus B, 60(3), 318-329, 2008.
Gerber, H. E.: Relative-humidity parameterization of the Navy aerosol model (NAM), NRL Report 8956, National Research Laboratory, Washington, D.C., USA, 1985.

Ginoux, P., Prospero, J. M., Torres, O., and Chin, M.: Long-term simulation of global dust distribution with the GOCART model: Correlation with North Atlantic Oscillation, Environ. Modell. Softw., 19(2), 113-128, 2004.

Gong, S. L., Barrie, L. A., and Blanchet, J. P.: Modeling sea salt aerosols in the atmosphere: 1. Model development, J. Geophys. Res., 102, 3805-3818, 1997.

Hamill, P., Turco, R. P., Kiang, C. S., Toon, O. B., and Whitten, R. C.: An analysis of various nucleation mechanisms for sulfate particles in the stratosphere, J. Aerosol Sci., 13, 561-585, 1982.

Henzing, J. S., Olivié, D. J. L., and van Velthoven, P. F. J.: A parameterization of size resolved below cloud scavenging of aerosols by rain, Atmos. Chem. Phys., 6, 3363-3375, 2006, http://www.atmos-chem-phys.net/6/3363/2006/.

Hirsikko, A., Bergman, T., Laakso, L., Dal Maso, M., Riipinen, I., Hõrrak, U., and Kulmala, M.: Identification and classification of the formation of intermediate ions measured in boreal forest, Atmos. Chem. Phys., 7, 201-210, 2007, http://www.atmos-chem-phys.net/7/201/2007/.

IPCC: Climate Change 2007: The Physical Scientific Basis, edited by: Solomon, S., Qin, D., Manning, M., et al., Cambridge Univ. Press, New York, USA, 2007.

Jacobson, M. Z. and Turco, R. P.: Simulating condensational growth, evaporation and coagulation of aerosols using a combined moving and stationary size grid, Aerosol Sci. Tech., 22, 73-92, 1995.

Jacobson, M., Turco, R., Jensen, E. and Toon O.: Modeling coagulation among particles of different composition and size, Atmos. Environ., 28, 1327-1338, 1994.

Kärcher, B. and Yu, F.: The role of aircraft soot emissions in contrail formation, Geophy. Res. Lett., 36, L01804, doi:10.1029/2008GL036649, 2009.

Kittelson, D., Johnson, J., Watts, W., et al.: Diesel aerosol sampling in the atmosphere, SAE Paper No. 2000-01-2212, 2000.

Kittelson, D. B., Watts, W. F., and Johnson, J. P.: On-road and laboratory evaluation of combustion aerosols - Part1: Summary of diesel engine results, J. Aerosol Sci., 37, 913-930, 2006.

Kuang, C., McMurry, P. H., McCormick, A. V., and Eisele, F. L. Dependence of nucleation rates on sulfuric acid vapor concentration in diverse atmospheric locations, J. Geophys. Res., 113, D10209, doi:10.1029/2007JD009253, 2008.

Laakso, L., Gagné, S., Petäjä, T., Hirsikko, A., Aalto, P. P., Kulmala, M., and Kerminen, V.-M.: Detecting charging state of ultra-fine particles: instrumental development and ambient measurements, Atmos. Chem. Phys., 7, 1333-1345, 2007, http://www.atmos-chem-phys.net/7/1333/2007/.

Laakso, L., Laakso, H., Aalto, P. P., et al.: Basic characteristics of atmospheric particles, trace gases and meteorology in a relatively clean Southern African Savannah environment, Atmos. Chem. Phys., 8, 4823-4839, 2008,

http://www.atmos-chem-phys.net/8/4823/2008/.

Li, J., Wong, J. G. D., Dobbie, J. S., and Chýlek, P.: Parameterization of the optical properties and growth of sulfate aerosols, J. Atmos. Sci., 58, 193-209, 2001.

Li, Q., Jiang, J. H., Wu, D. L., et al.: Convective outflow of South Asian pollution: a global CTM simulation compared 
with EOS MLS observations, Geophys. Res. Lett., 32, L14826, doi:10.1029/2005GL022762, 2005.

Liao H., Henze, D. K., Seinfeld, J. H., Wu, S., and Mickley, L. J.: Biogenic secondary organic aerosol over the United States: Comparison of climatological simulations with observations, J. Geophys. Res., 112, D06201, doi:10.1029/2006JD007813, 2007.

Liu, H., Jacob, D. J., Bey, I., and Yantosca, R. M.: Constraints from $210 \mathrm{~Pb}$ and $7 \mathrm{Be}$ on wet deposition and transport in a global threedimensional chemical tracer model driven by assimilated meteorological fields, J. Geophys. Res.-Atmos., 106, 12 109-12 128, 2001.

Makkonen, R., Asmi, A., Korhonen, H., et al.: Sensitivity of aerosol concentrations and cloud properties to nucleation and secondary organic distribution in ECHAM5-HAM global circulation model, Atmos. Chem. Phys., 9, 1747-1766, 2009, http://www.atmos-chem-phys.net/9/1747/2009/.

Mark, G., Kuhns, H., Pitchford, M., Dietz, R., Ashbaugh, L., and Watson, T.: Application of the Tracer-Aerosol Gradient Interpretive Technique (TAGIT) to sulfur attribution for the Big Bend Regional Aerosol and Visibility Observational (BRAVO) Study, JAPCA J. Air Waste Ma., 53, 586-595, 2003.

Martin, R. V., Jacob, D. J., Yantosca, R. M., Chin, M., and Ginoux, P.: Global and regional decreases in tropospheric oxidants from photochemical effects of aerosols, J. Geophys. Res., 108, 4097, doi:10.1029/2002JD002622, 2003.

Nenes, A., Pandis, S. N., and Pilinis, C.: ISORROPIA: A new thermodynamic equilibrium model for multiphase multicomponent inorganic aerosols, Aquat. Geochem., 4, 123-152, 1998.

NRC: Radiative Forcing of Climate Change: Expanding the Concept and Addressing Uncertainties, National Academies Press, 2005.

O’Dowd, C. D., Smith, M. H., Consterdine, I. E., and Lowe, J. A.: Marine aerosol, sea salt, and the marine sulpher cycle: A short review, Atmos. Environ., 31, 73-80, 1997.

Olivier, J. G. J., Berdowski, J. J. M., Peters, J. A. H. W., Bakker, J., Visschedijk, A. J. H., and Bloos, J.-P. J.: Applications of EDGAR. Including a description of EDGAR 3.0: reference database with trend data for 1970-1995. RIVM, Bilthoven. RIVM report no. 773301 001/ NOP report no. 410200 051, 2001.

Pan, W., Tatang, M. A., McRae, G. J., and Prinn, R. G.: Uncertainty analysis of indirect radiative forcing by anthropogenic sulfate aerosols, J. Geophys. Res., 103(D4), 3815-3823, 1998.

Park, R. J., Jacob, D. J., Field, B. D., Yantosca, R. M., and Chin, M.: Natural and transboundary pollution influences on sulfate-nitrate-ammonium aerosols in the United States: Implications for policy, J. Geophys. Res., 109, D15204, doi:10.1029/2003JD004473, 2004.

Park, R. J., Jacob, D. J., Chin, M., and Martin, R. V.: Sources of carbonaceous aerosols over the United States and implications for natural visibility, J. Geophys. Res., 108, 4355, doi:10.1029/2002JD003190, 2003.

Park, R. J., Jacob, D. J., Kumar, N., and Yantosca, R. M.: Regional visibility statistics in the United States: Natural and transboundary pollution influences, and implications for the Regional Haze Rule, Atmos. Environ., 40, 5405-5423, 2006.

Park, R. J., Jacob, D. J., Palmer, P. I., et al.: Export efficiency of black carbon aerosol in continental outflow: global implications, J. Geophys. Res., 110, D11205, doi:10.1029/2004JD005432, 2005.
Pierce, J. R. and Adams, P. J.: Global evaluation of ccn formation by direct emission of sea salt and growth of ultrafine sea salt, J. Geophys. Res., 111, D06203, doi:10.1029/2005JD006186, 2006.

Pierce, J. R., Chen, K., and Adams, P. J.: Contribution of primary carbonaceous aerosol to cloud condensation nuclei: Processes and uncertainties evaluated with a global aerosol microphysics model, Atmos. Chem. Phys., 7, 5447-5466, 2007, http://www.atmos-chem-phys.net/7/5447/2007/.

Pierce, J. R. and Adams, P. J.: Uncertainty in global CCN concentrations from uncertain aerosol nucleation and primary emission rates, Atmos. Chem. Phys., 9, 1339-1356, 2009, http://www.atmos-chem-phys.net/9/1339/2009/.

Riipinen, I., Sihto, S.-L., Kulmala, M., et al.: Connections between atmospheric sulphuric acid and new particle formation during QUEST III-IV campaigns in Heidelberg and Hyytiälä, Atmos. Chem. Phys., 7, 1899-1914, 2007,

http://www.atmos-chem-phys.net/7/1899/2007/.

Spracklen, D. V., Carslaw, K. S., Kulmala, M., eta 1.: Contribution of particle formation to global cloud condensation nuclei concentrations, Geophys. Res. Lett., 35, L06808, 2008.

Spracklen, D. V., Pringle, K. J., Carslaw, K. S., Chipperfield, M. P., and Mann, G. W.: A global off-line model of size-resolved aerosol microphysics: I. Model development and prediction of aerosol properties, Atmos. Chem. Phys., 5, 2227-2252, 2005a, http://www.atmos-chem-phys.net/5/2227/2005/.

Spracklen, D. V., Pringle, K. J., Carslaw, K. S., Chipperfield, M. P., and Mann, G. W.: A global off-line model of size-resolved aerosol microphysics: Ii. Identification of key uncertainties, Atmos. Chem. Phys., 5, 3233-3250, 2005b, http://www.atmos-chem-phys.net/5/3233/2005/.

Spracklen, D. V., Carslaw, K. S., Kulmala, M., Kerminen, V.-M., Mann, G. W., and Sihto, S.-L.: The contribution of boundary layer nucleation events to total particle concentrations on regional and global scales, Atmos. Chem. Phys., 6, 5631-5648, 2006, http://www.atmos-chem-phys.net/6/5631/2006/.

Streets, D. G., Bond, T. C., Carmichael, G. R., et al.: An inventory of gaseous and primary aerosol emissions in Asia in the year 2000, J. Geophys. Res., 108, 8809, doi:10.1029/2002JD003093, 2003.

Suni, T., Kulmala, M., Hirsikko, A., et al.: Formation and characteristics of ions and charged aerosol particles in a native Australian Eucalypt forest, Atmos. Chem. Phys., 8, 129-139, 2008, http://www.atmos-chem-phys.net/8/129/2008/.

Toon, O. B., Turco, R. P., Westphal, D., Malone, R., and Liu, M. S.: A multidimensional model for aerosols: Description of computational analogs, J. Atmos. Sci., 45, 2123-2143, 1988.

Trivitayanurak, W., Adams, P. J., Spracklen, D. V., and Carslaw, K. S.: Tropospheric aerosol microphysics simulation with assimilated meteorology: model description and intermodel comparison, Atmos. Chem. Phys., 8, 3149-3168, 2008, http://www.atmos-chem-phys.net/8/3149/2008/.

Turco, R. P., Hamill, P., Toon, O. B., Whitten, R. C., and Kiang, C. S.: A one-dimensional model describing aerosol formation and evolution in the stratosphere, Part I, Physical processes and mathematical analogs, J. Atmos. Sci., 36, 699-717, 1979.

Twomey, S.: The influence of pollution on the shortwave albedo of clouds, J. Atmos. Sci., 34, 1149-1152, 1977. 
Varutbangkul, V., Brechtel, F. J., Bahreini, R., et al.: Hygroscopicity of secondary organic aerosols formed by oxidation of cycloalkenes, monoterpenes, sesquiterpenes, and related compounds, Atmos. Chem. Phys., 6, 2367-2388, 2006, http://www.atmos-chem-phys.net/6/2367/2006/.

Venzac, H., Sellegri, K., Laj, P., et al.: High frequency new particle formation in the Himalayas, P. Natl. Acad. Sci. USA, 105, 15 666-15 671, 2008.

Vestreng, V., Myhre, G., Fagerli, H., Reis, S., and Tarrasón, L.: Twenty-five years of continuous sulphur dioxide emission reduction in Europe, Atmos. Chem. Phys., 7, 3663-3681, 2007, http://www.atmos-chem-phys.net/7/3663/2007/.

Wang, M. and Penner, J. E.: Aerosol indirect forcing in a global model with particle nucleation, Atmos. Chem. Phys., 9, 239-260, 2009 , http://www.atmos-chem-phys.net/9/239/2009/.

Weimer, S., Mohr, C., Richter, R., et al.: Mobile measurements of aerosol number and volume size distributions in an Alpine valley: Influence of traffic versus wood burning, Atmos. Environ., 43, 624-630, 2009.

Wesely, M. L.: Parameterization of Surface Resistances to Gaseous Dry Deposition in Regional-Scale Numerical-Models, Atmos. Environ., 23, 1293-1304, 1989.

Whitby, K. T., Cantrell, B. K., and Kittelson, D. B.: Nuclei formation rates in a coal-fired power plant plume, Atmos. Environ., 12, 313-321, 1978.

Whitby, K.: The physical characteristics of sulfur aerosols, Atmos. Environ., 12, 135-159, 1978.

Yevich, R. and Logan, J. A.: An assessment of biofuel use and burning of agricultural waste in the developing world, Global Biogeochem. Cy., 17(4), 1095, doi:10.1029/2002GB001952, 2003.
Yu, F. and Turco, R. P.: Case studies of particle formation events observed in boreal forests: Implications for nucleation mechanisms, Atmos. Chem. Phys., 8, 6085-6102, 2008, http://www.atmos-chem-phys.net/8/6085/2008/.

Yu, F. and Turco, R. P.: The role of ions in the formation and evolution of particles in aircraft plumes, Geophys. Res. Lett., 24, 1927-1930, 1997.

Yu, F., Wang, Z., Luo, G., and Turco, R. P.: Ion-mediated nucleation as an important source of tropospheric aerosols, Atmos. Chem. Phys., 8, 2537-2554, 2008,

http://www.atmos-chem-phys.net/8/2537/2008/.

Yu, F.: A Study of the Formation and Evolution of Aerosols and Contrails in Aircraft Wakes: Development, Validation and Application of an Advanced Particle Microphysics (APM) Model, Doctoral Dissertation, UCLA, 1998.

Yu, F.: From molecular clusters to nanoparticles: Secondgeneration ion-mediated nucleation model, Atmos. Chem. Phys., 6, 5193-5211, 2006, http://www.atmos-chem-phys.net/6/5193/2006/.

Yu, F.: Ion-mediated nucleation in the atmosphere: Key controlling parameters, implications, and look-up table, J. Geophy. Res., 114, doi:10.1029/2009JD012630, in press, 2009.

Zhang, L. M., Gong, S. L., Padro, J., and Barrie, L.: A size segregated particle dry deposition scheme for an atmospheric aerosol module, Atmos. Environ., 35, 549-560, 2001.

Ziemba, L. D., Griffin, R. J., and Talbot, R. W.: Observations of elevated particle number concentration events at a rural site in New England, J. Geophys. Res., 111, D23S34, doi:10.1029/2006JD007607, 2006. 